مجلة جامعة الملك عبدالعزيز: الآداب والعلوم الانسانية، م29ع3 ص ص: 309- 336 (2021م) DOI:10.4197/Art.29-3.11

\title{
رمزية "الوادي الكبير" في الثعر الأندلسي والإسباني \\ دراسة مقارنة في نماذج مختارة 1
}

مستخلص. تعالج الدراسة الماثلة ظاهرة جلية تحظى بتمثيلات لافتة في الثعر الإسباني قديمًا وحديثًا، تكمن في انتحال نهر "الوادي الكبير" الشهير في الجنوب الإسباني، رمزًا تجرب به القصيدة تجسيد التجاذب الدائم بين الإنسان والظواهر الوجودية من حوله. وترمي القراءة إلى تحليل هذه العلاقة وتفكيكها في علامات كبرى تستولي عليها ثنائية الموت والحياة وما يندرج فيها ويتفرع عنها، بوصفها الأصل الموضوعي الذي يمثل نهر الوادي الكبير معادله الأدق الكقدي ونموذجه الأصدق لدى الثاعر الإسباني. وقد انتخبت الدراسة متونًا من الثعر الإسباني في القديم والحديث لأهم

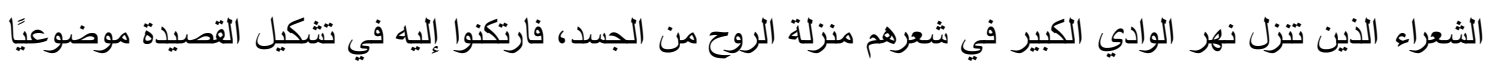

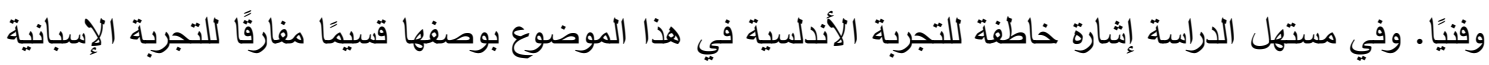

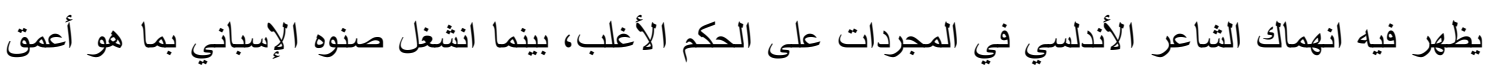
من ذلك، تحدوه القيمة الوجودية العليا لنهر الوادي الكبير • كلمات مفتاحية: الثعر الإسباني، الرمزية، الوادي الكبير •

ثنائية "الماء-الوجود" سرعان ما استحالت ضربًا من

التماهي الغائر في فكر الإنسان ووجدانه. ومن البدهي الإنسان والماء أن يؤلف الماء بشتى تمثيلاته المادية ظاهرة من أهم لا شك أن صلة الكائن البشري بعنصر الماء قديمة

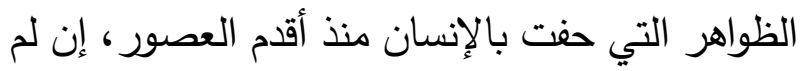

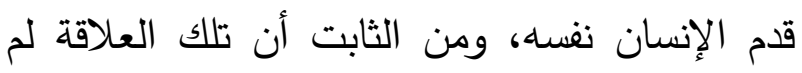
تكن أهمها؛ والدليل شدة انفعاله بها حتى غدت جزئًا

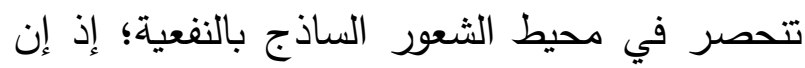


الأخرى ما يوطل هذه الفكرة كما هو الحال مع هيكل

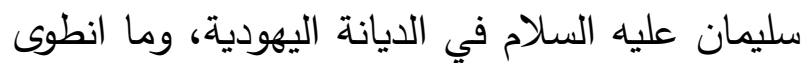
عليه "المطهر" فيه من دلالة النقاء البدني المفضي لئي

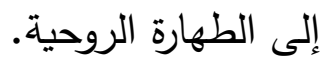
ولا نغفل كذلك عن أن الماء، زيادة على فعل التطهير

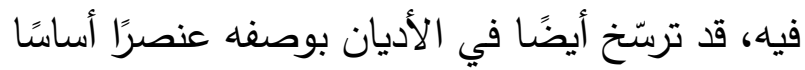
للنعيم الأبدي في الجنة مقابل نعيم الدنيا المشاكل له، لهانه

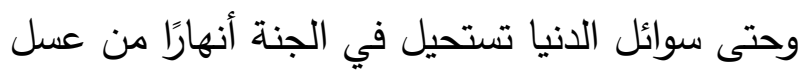

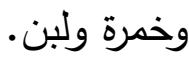

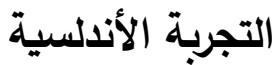

شغل الماء منذ القدم حيزًا في الثعر العربي، لا بوصفه

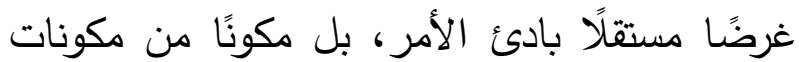
القصيدة، ومادة ملهمة للخيال الثعري. وتعد ظاهرة

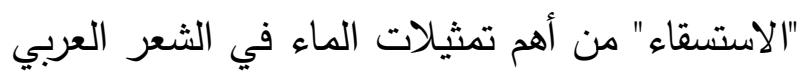
القديم؛ فقد نعمت بحضور لافت داخل القصيدة بوصفها علامة على البقاء في بيئة قاسية يتمثل فيها الموت تمثل الحياة، ما جعلهم يستسقون للميت والحي على حد سواء، وكأن دور الماء يتجاوز استدامة الحياة إلى التطلع لاستخلاصها من الموت نفسه ولو كان معنويًا على الأقل.

ورغم أن انفعال الثاعر بالطبيعة من حوله فطري

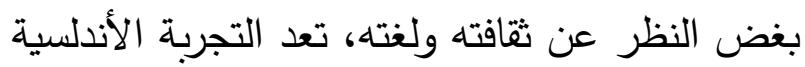

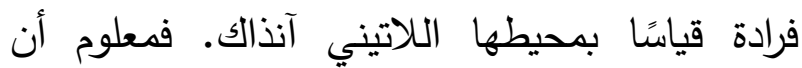

والأحلام، ترجمة: علي نجيب إبراهيم، بيروت: المنظمة العربية للنشر،

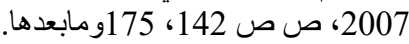
2 الأنبياء: 30 صن صن 3 للمزيد عن موضوع التطهير، انظر باثلار، غاستون، الماء و الأحلام،

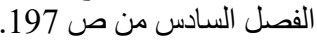

لا يتجزأ من عاطفته وخياله، فاستحثت فيه مشاعر الحب والخوف والأمل وغير ذلك. وثمرةً لهذا الانجذاب الطاغي الذي لازم الإنسان منذ أعتق العصور؛ تحول الماء إلى مادة رئيسة للأديان

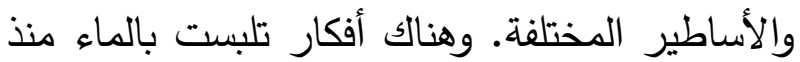
القدم وتعلقت به حتى استقرت رموزًا وإشارات؛ كعلاقته بالخصوبة والتكاثر من جهة كونه الوسيلة الأولى التى للتخلق البشري ومن ثم البقاء والاستمرار1، وهذا ما دانه صادق عليه النص الديني حين قرنه بالحياة على

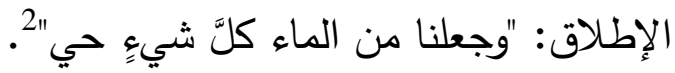
وتظل فكرة التطهير الملازمة للماء في طليعة ما يمكن أن يشار إليه في هذا الصدد، وهي المسؤولة في الغالب عن قدسنته وجعله قضية دينية بالدرجة الأولى 3. وفي التراث الديني على اختلاف مصادره ما يجسد هذا الاقتران ويرسخه؛ ففي القرآن الكريم مثلًا، الأل هنالك محورية طاغية للماء في فعل التطهير من الدنس في هيئته المعنوية وليس الحسية فقط، حتى في سياق الحديث عن الهلاك والدمار ؛ كما هو الحال في قصة نوح عليه السلام حين كان الطوفان سببًا مباشرًا في طهارة للأرض من بغي العتاة والمفسدين، ومثله في قصة غرق فرعون في البحر وخلاص موسى عليه السلام وقومه، وما تضمنته من رمزية التطهير الذي في لئي أراح الأرض من الظلم والجبروت. وفي التقاليد الدينية

1 يشير باشلار في كتاب الماء والأحلام إلى ثنائية الماء-الحليب باعتبار هما

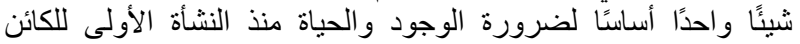

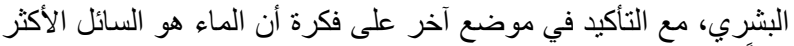

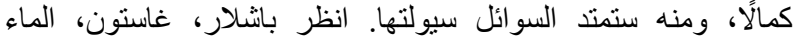


ووداع وصخب وهدوء. لقد كان ملهمًا بالقدر الذي يمكن تثبيهه بآلهة اليونان وربات الثعر ودهر عند العرب. وفي سياق مشابه، يقول ابن ظافر الأزدي: "وركب لئبن

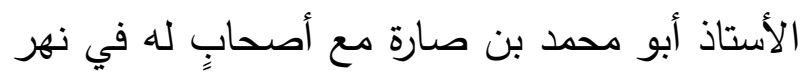

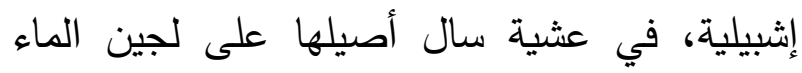

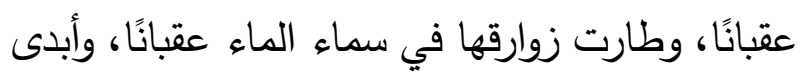

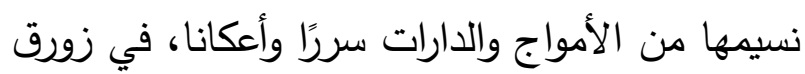
يجول جولان الطرف، ويسود اسوداد الطرف، فقال بديهًا:

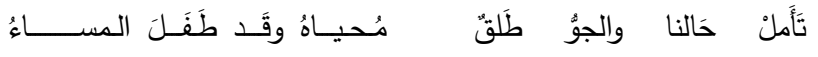

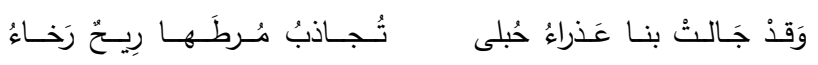

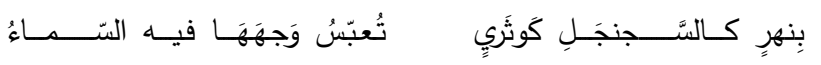

واتفق أن وقف أبو إسحاق ابن خفاجة على القطعة، فاستظرفها واستطابها، فقال يعارضها على إنى وزنها

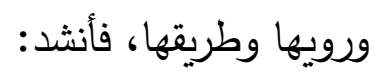

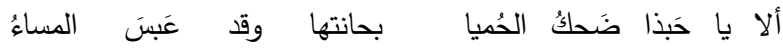
وأدهم من جيادِ الماء نهذٍ

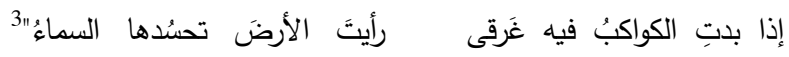

وفي شعر الطبيعة الأندلسي ما يمكنه أن يحد من

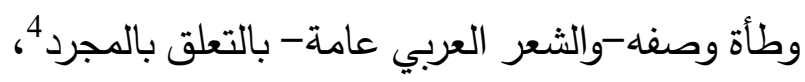

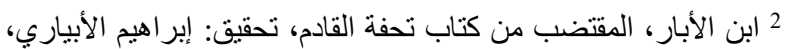

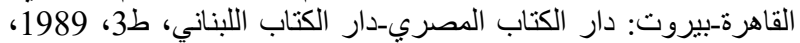

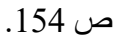
3 ابن ظافر الأزدي، علي، بدائع البدائه، ضبطه وصحص، وصحه: مصطفى عطا،

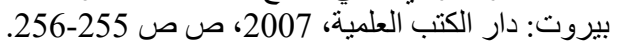

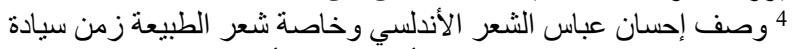

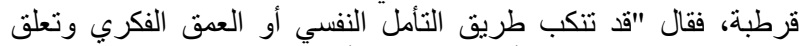

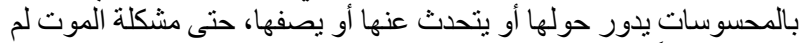

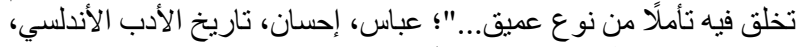

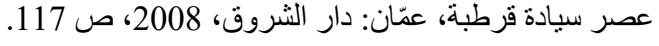

الأندلسيين تعلقوا ببيئتهم على نحو معمق تجسد في شعرهم فامتازوا بكثافة التصوير والانهماك في تفاصيل

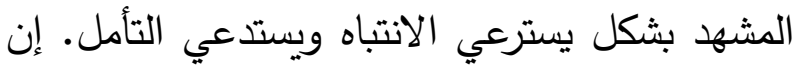

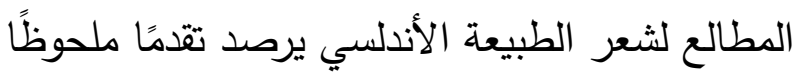
في وعي الثاعر بها، وبعنصر الماء الذي يعتبر مكونًا

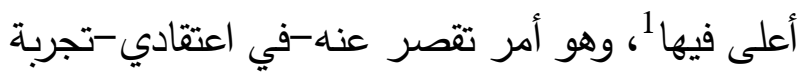
جيرانهم المسيحيين آنذالك؛ إذ تأخر وعيهم بها على ألى نحو لافت، إلى عهد فراي لويس ذي ليون (15281591 م) ولويس ذي غونغورا (1561-1627م) مثلًا، وهي مساهمات واعية في هذا الصدد أعقبت سقوط الأندلس ونهاية الوجود العربي فيها. وعطفًا على تلك الأهمية، فقد ترك أثرًا بليغًا عند

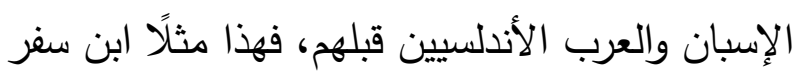

$$
\text { المريني يقول عن الوادي الكبير² }
$$

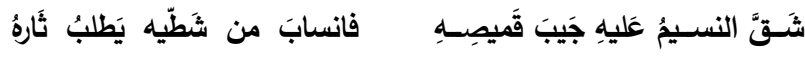

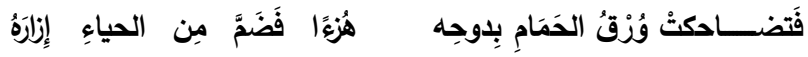

لقد شخص النهر فصوره على هيئة بشر بإحساس مفعم وإرادة كاملة، وهو أمر ليس بمستغرب إذا ما لئل

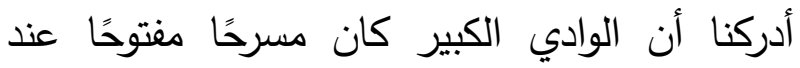

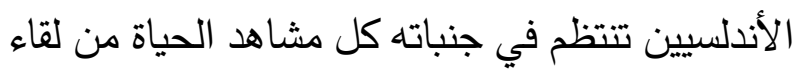

1 للمزيد حول الأندلس و علاقته بالماء، خاصة في الشعر ، انظر مثلًا:

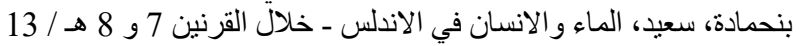

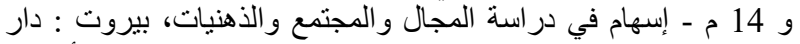

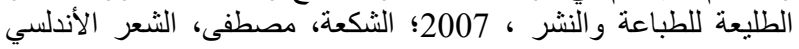

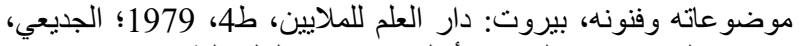

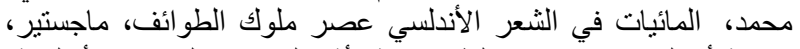

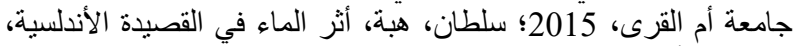
الجامعة الأردنية، ماجستير، 
بالوجود دون الوصول لأبعد من مجرد الوقفة العابرة؛ لانغماس الثاعر في عنصر التشخيص وافتتانه بتخليق الصور . تأمل قول الثاعرة حمدونة بنت زياد المؤدب4

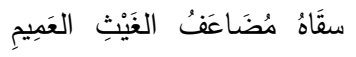

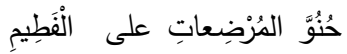

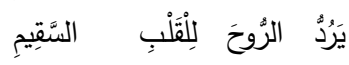

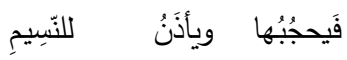

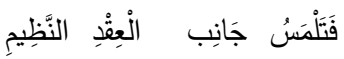

على أن الرؤية الحديثة لا تعد تلك النصوص في مستوى الوعي الفلسفي النافذ إلى بواطن الأمور؛ فالتشخيص الدقيق الذي يخلّق الماء في هيئة كائن بشري، لا يفي بغرض هذه الدراسة التي تتغيا حالة

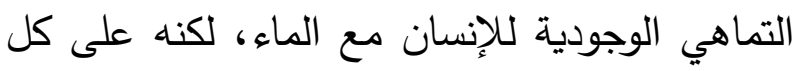
حال وسيلة الثاعر لتأمل ظاهرة الماء والتعبير عن انفعاله الوجداني بها. هذا ابن خفاجة يعبر باعتناء دقيق عن الماء في معرض وصفه لبعض الثريات1

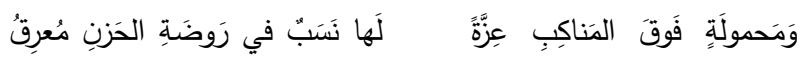

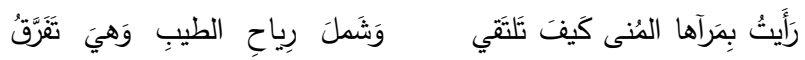

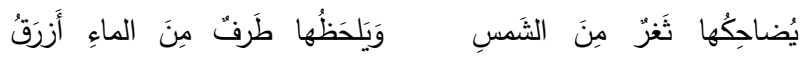

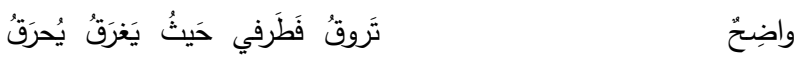
وَتُجلى بِهِا لِلماءِ وَالنارِ صورة

ففي البيت الأخير استدعاء لفكرة فلسفية تحفل بجمع النقيضين: الماء والنار ، في مشهر واحد لا يلغي لاني أحدهما فيه الآخر، وهو في هذاء يعيدنا للشاعر العباسي أبي نواس حينما جمع في الثلج صفتي البرودة والحرارة2:

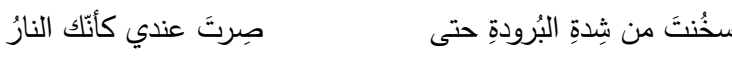

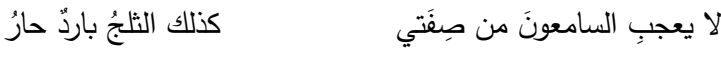

وقد عقب ابن رشيق على هذين البيتين بقوله: "فهذا

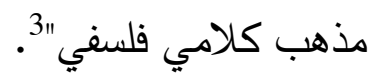
إن في الثعر الأندلسي، في موضوع الطبيعة ومنها

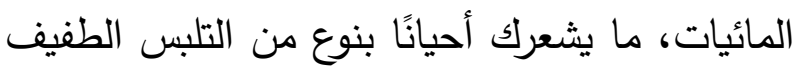

1 ابن خفاجة، ديوان، تحقيق: عبد الله سندة، بيروت: دار المعرفة،

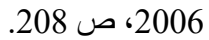

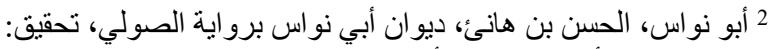

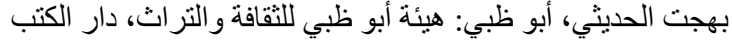

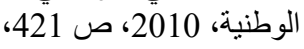


مغلقًا في نظام بعينه، وإنما توجه اهتمامها إلى التى

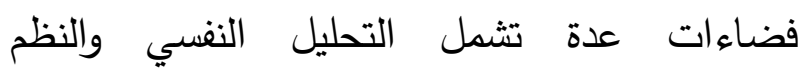
الاقتصادية و والاجتماعية والأيديولوجيا ونظرية لفية الخطاب...2. وعلى الرغم من عظم الانتفاع الذي واعنيه يبشر به هذا الانفتاح في تحليل النصوص؛ لن تتسع سنع

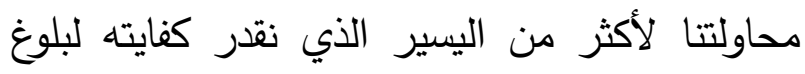

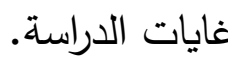
شريحة الدراسة لا يخفي ما يلحق عملية الاختيار من صعوبات

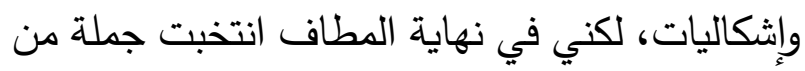
النصوص قدرت فيها الكفاية للوفاء بتطلعات الدراسات، وكنت ميالًا إلى تلك النصوص النهابل التي تثعر بوجود تقاطعات مشتركة وتجربة يمكن تعميمها على ميلى كل نصٍ حديثٍ موضوعه الماء. لذلك وقع الاختيار على نصوص قديمة تعود لشعراء إسبان بارزين من القرن الخامس عشر والسادس عشر، وحديثة لنخبة من شعراء القرن العشرين تعكس في جملتها اتصال التجربة الشعرية الإسبانية في هذا الموضوع تحديدًا. والجدير بالذكر هنا أننا لن نعدم من الباحثين -الإسبان على حد علمي- من حاول الوقوف على علاقة الماء بالوجود الإنساني من خلال نهر الوادي الكبير. لقد أشارت بعض الدراسات الإسبانية إلى هذه العلاقة عند الإنداني

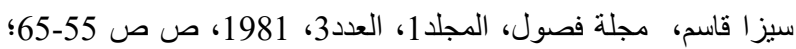
شولز، روبرت، السيمياء والتأويل، ترجمة: سعيد الغانمي، بيروت

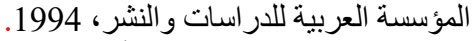
2 شولز، روبرت، السيمياء والتأويل، ص صليت، 15.
الذي يخترق أجزاء واسعة من جنوب إسبانيا وصولًا

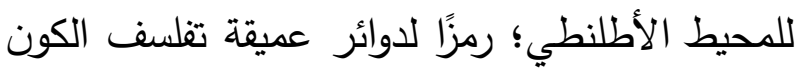

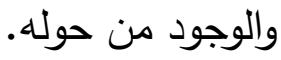
بين يدي الدراسة تجتهد الدراسة الحاضرة في الإجابة عن جملة من التساؤلات يمكن إجمالها في التالي: هل بلغ الثاعر الإسباني حد التماهي مع الطبيعة من خلال نموذج نهر الوادي الكبير، أم بقي في إطار التصوير التسجيلي الفوتوغرافي تارة، والمناوشة المحدودة تارة أخرى كما غلب على نظيره الأندلسي؟ وما الظواهر الكبرى المعبرة عن هذا التماهي في حال حدوثه فعلاً؟

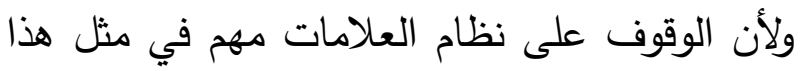
اللون من الدراسات، ستكون إجراءات المنهج السيميائي 1 أداة معينة للدراسة لتجلية التجربة الثعرية والوقوف على أبرز معالمها. ومن المعلوم أن تركيز هذا الحقل على دور العلامات

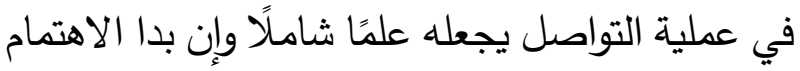
به في جانب اللغة كبيرًا، فاللغة نظام من العلاقات أيضًا مقترنة بأفكار كغيرها من الدوال غير اللغوية مثل إثارة المرور أو تفاصيل الوشم وغير ذلك. إن النظام اللغوي الكامن في موضوع بعينه من الشعر،

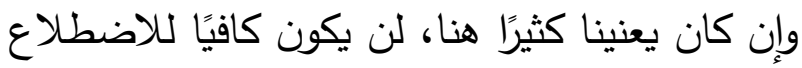

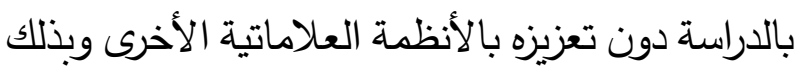

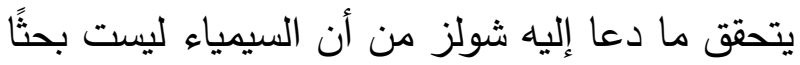

1 حول المنهج السيميائي انظر أعمال سعيد بنكراد مثل: السيميائيات

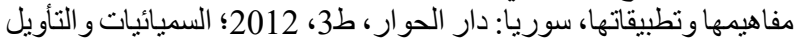

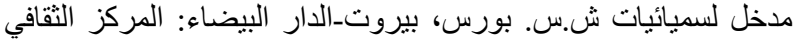
العربي، 2005 ـ و انظر بنفنيست، إميل، السيميولوجيا وليفياء اللغة، ترجمة: 
مقاطعة جيان، حتى سانلوكار (Sanlúcar) أو شلوقة في مقاطعة قادس. وتعود أهميته على الأرض كونه ينبسط على مساحة معتبرة، ويقوم على تغذية أجزاء واسعة من الجنوب الأندلسي بروافده الكثيرة كنهر شنيل (Genil) وكما استُتج سابقًا، فإن الثاعر الأندلسي تقاسم مع صنوه الإسباني نزعة التفاعل مع المياه الجارية بوصفها مكتسبات في المستوين المعيثي والنغسي. والسؤال الذي يتجدد هنا: إذا تقرر أن الشاعر الأندلسي لم يتجاوز ملامسة الفكرة فيما يخص قيمة الماء دون أن يدلف إلى بواطن العلاقة معه من جهة الجانب الوجودي الرمزي؛ فهل كان الثاعر الإسباني القديم المجايل له أو الواقع في محيطه الزمني الكبير مثله،

أم عبر على نحو مختلف حقيق بالوقوف والتأمل؟ هذا لويس ذي غونغورا (1561-1627 م)33 من شعراء القرنين السادس عشر والسابع عشر يقول عن نهر الوادي الكبير

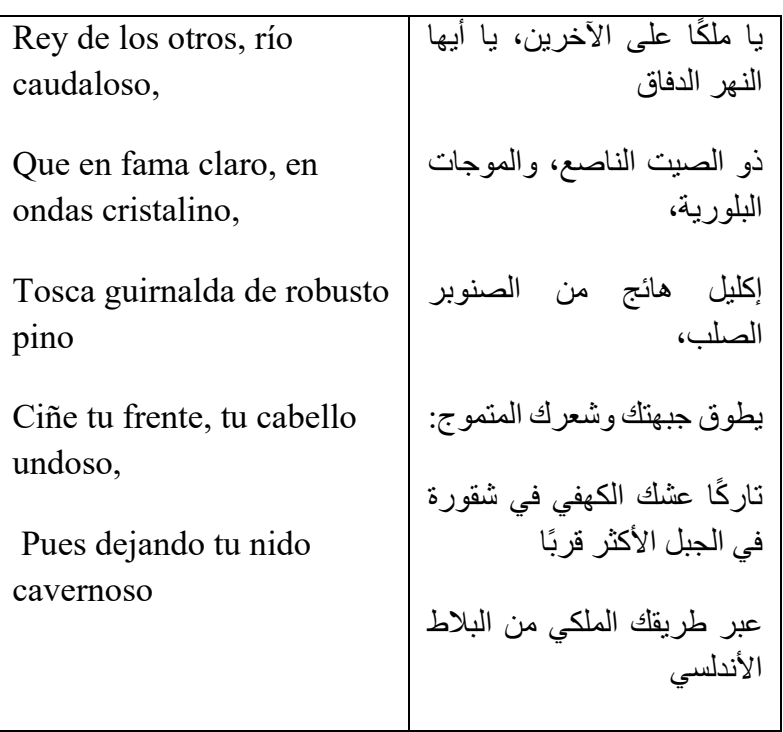

شعراء إسبان محدثين غالبًا 1، لكنها لا تعدو أن تكون مناوشات عابرة للفكرة في نصوص الوادي الكبير ولم تشكل همًا بحثيًا منذ الأساس. وعلى كل حال تظل فكرة الماء والإنسان بدهية لا تمثل جدة في عنوانها العريض؛ إذ إنها ثنائية -كما سبق أن أشرنا في موضع سابق -متلازمة منذ القدم، ولعل الدراسة الحاضرة تكون أكثر رسوخًا وجدية في معالجة الظاهرة عبر نصوص لشعراء الوادي الكبير؛ كونها توفرت على العلامات العميقة لهذه العلاقة وناقثتها-في زعمنا-على نحو متأن وباستقراء عام. رمزية الوادي الكبير في الثعر الإسباني القديم: يقع نهر الوادي الكبير أو Guadalquivir إسبانيا، وكان يعرف قبل الوجود العربي بنهر بيتيس في الحقبة السابقة للعهد الروماني. يخترق (Betis) مواضع أندلسية عدة كجيان وقرطبة وإشبيلية منتهيًا إلى المحيط الأطلسي، ويمتد بطول 657 كم أو أكثر من سلسلة جبال كاثورلا (Sierra de Cazorla) من

1 من هذه الدر اسات يمكن أن نذكر:

Pineda Novo, Daniel. "Antonio Machado, exegeta del Guadalquivir". Boletín del Instituto de Estudios Giennenses, N. 66, 1970, pp. 41-68; Jiménez Martos, Luis. Abrazo al Guadalquivir. Colección Córdoba. Diario Córdoba y Cajasur 1996;

Solano Márquez, Francisco. Un río de versos. Rincones de Córdoba con encanto. Diario Córdoba 2003.

2 عن نهر الوادي الكبير وتاريخه الضارب في عمق أوروبا؛ انظر Eslava Galán, Juan, Viaje por el Guadalquivir y su Historia, Madrid: La Esfera de los Libros, 2016. إسلابا (إ) (إ) إي الان، خوان، رحلة في الوادي الكبير وتاريخه) 3 لويس ذي غونغورا إي أرغوتي (Luis de Góngora y Argote)،

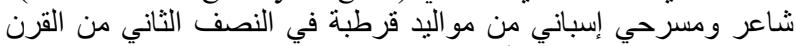

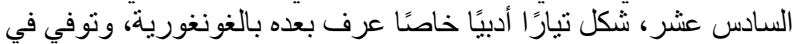

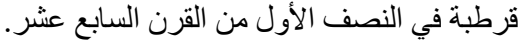


وإذا جاز القول بإمكانية اتصال غونغورا بالثعر الأندلسي واطلاعه عليه وتأثره به؛ فإن القارئ لعدد من نصوص شعره عن الوادي الكبير -كالمترجم أعلاه

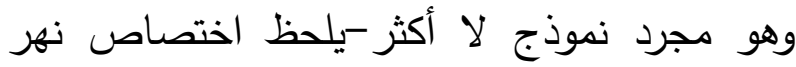
الوادي الكبير بكامل المقطوعة؛ إذ يبسط الثاعر حديثه فيه وعنه عاكيًا مساحة الأثر في نفسه تجاه هذا النهر؛ في حين أن الثاعر الأندلسي لا يرابط

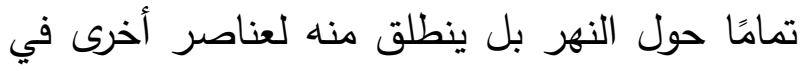

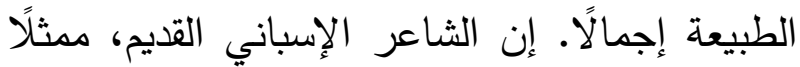

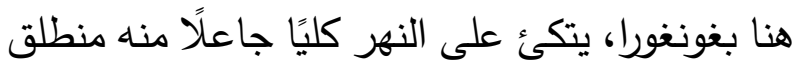
الفكرة وأساسها لا يكاد يجاوزه إلى غيره، بينما شغل

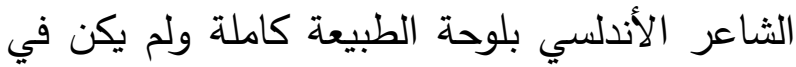
تقاليده الثعرية التركيز في عنصر بعينه، حتى فيما

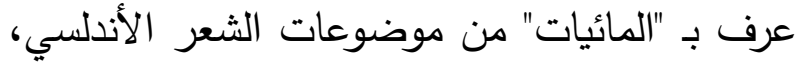

\begin{tabular}{|l|l|}
\hline $\begin{array}{l}\text { Has visto, que en tus aguas } \\
\text { se han mirado, }\end{array}$ \\
Beldad cual la de Clori, o \\
gracia tanta.
\end{tabular}

${ }^{4}$ de Góngora y Argote, Luis. poesías escogidas,

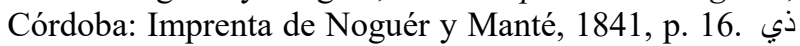
(غونغور ا، لويس، قصائد مختارة).

كل الترجمات الواردة للنصوص الإسبانية في هذه الدراسة هي من عمل

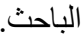

Naranjo Mesa, Jorge Alberto. Poesía del 1 . Colombia: Universidad Renacimiento y el Barroco de Antioquia, 2005, pp. 85-94.

$$
\begin{aligned}
& \text { (نار انخو ميسا، خورخي ألبرتو. شعر عصر النهضة و البارّوكو) }
\end{aligned}
$$

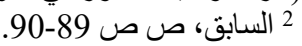

$$
\begin{aligned}
& 3 \text { ابن خفاجةـ ديوان، تحقيق: عبد الله سندة، بيروت: درا المعرفة، 2006، }
\end{aligned}
$$

اقترح أحد الدارسين للشاعر غونغورا تسميته بـ "شاعر الوادي الكبير"؛ عطفًا على كم النصوص الثعرية التي كرسها لهذا النهر وشدة تفاعله معه1. والحق أن الوقوف على نصوصه التي خصصها للوادي الكبير مدهش من جهتين؛ أولًا: عمق تعاطيه مع هذا النهر وتتصيبه لله رمزًا للفخامة والزعامة، وجعله علامة حيوية لأندالوثيا كلها وقرطبة تحديدًا، وثانيًا تقاطعه مع الثاعر العربي الأندلسي في تشخيصه له؛ فيجعله مرة رسولًا للمحبين، ومرة قبلة للغرام، ومرة عينًا باصرة والأوراق من حوله أهدابًا2، وهذا الأخير مثًا يذكرنا بقول شاعر الطبيعة الأندلسي الأول؛ ابن خفاجة3 وغدت تحف به الغصون كأنها هدب يحف بمقلة زرقاء

\begin{tabular}{|c|c|}
\hline $\begin{array}{l}\text { De Segura en el monte } \\
\text { más vecino }\end{array}$ & بالزبدى، فخمًا، مندفعًا و وملينًا \\
\hline $\begin{array}{l}\text { Por el suelo andaluz tu real } \\
\text { camino }\end{array}$ & أطأ، مع أنى أن من شطيك الخصبين \\
\hline $\begin{array}{l}\text { Tuerces soberbio, raudo y } \\
\text { espumoso, }\end{array}$ & ذرات النبات المنت اضع \\
\hline $\begin{array}{l}\text { A mí, que de tus fértiles } \\
\text { orillas }\end{array}$ & قل لي إن كنت من بين الر اعيات \\
\hline $\begin{array}{l}\text { Piso, aunque ilustremente } \\
\text { enamorado, }\end{array}$ & اللو اتي نظرن فيك أنفسهن، \\
\hline $\begin{array}{l}\text { Tu noble arena con } \\
\text { humilde planta, }\end{array}$ & رأو سعادة جمة. \\
\hline $\begin{array}{l}\text { Dime si entre las rubias } \\
\text { pastorcillas }\end{array}$ & \\
\hline
\end{tabular}


لا يكاد الماء يستأثر بالحديث عن شراكة سائر تتلوى فخمًا، مندفعًا وملييًا بالزبد.

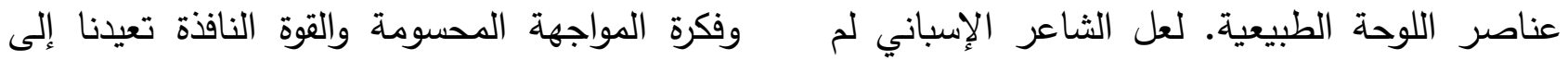
الشعر الأندلسي وثثائية النهر - السيف؛ فلا تكاد تجد ولهد يكن بالقدر نفسه من الانهماك في الطبيعة والنظر وصفًا لجدول أو نهر أندلسي إلا وتحضر فيه النيه صورة إليها بوصفها ذاتًا كلية، لذا محض القصيدة للنهر

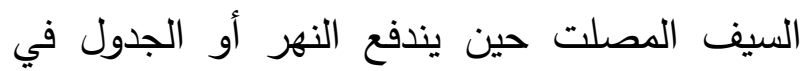

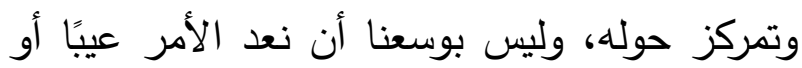
طريق مستقيم أو شبه مستقيم؛ يقول الثاعر يصف مزية بقدر ما هو تمثل للموضوع في نفس الثاعر عند

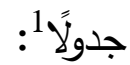
الفريقين. فإذا استقام رأيت صورة مصلت وإذا استدار رأيت شكل سوار ومن مظاهر المشاركة الوجدانية مع نهر الوادي الكبير عند الثاعر الإسباني القديم ممثلًا بغونغورا، ما نراه في نهاية المقطوعة نفسها حين نجده يستزل النهر سريعًا من عرش الملك والقوة ليطلب منه المعونة في تحصيل خبر حبيته "كلوري" من جهة كون النهر العظيم محطة تقف عليها الحسناوات تمامًا كما هو

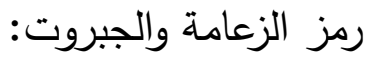
قل لي إن كنتَّ من بين الراعيات الثقراوات الصغيرات

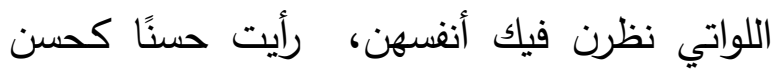
كلوري والحقيقة فهناك ملمح يستحق التأمل هنا وهو استيعاب الوادي الكبير للدلالات المتخالفة؛ فمن دلالة الفخامة والقسوة إلى البساطة والإنسانية التي استحال بها مرآة للحسناوات يقفن عندها ليتعهدن محاسنهن، وهو علاوة على ذلك لطيف مع العثاق يألفهر ويألفونه ويخبر عنهم ويقرب بينهم. ثم إن انسرابه بقوة يقابله وداعة

في مستهل حديثه عن النهر، يصنع غونغورا منه إنسانًا عظيمًا استأثر بالملك دون سائر الأنهار ، وهي المزية الثابتة التي يخلعها الثاعر على الوادي الكبير

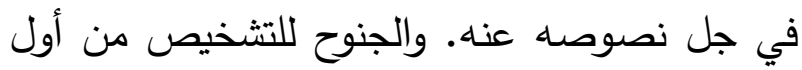
وهلة تصعيد للوادي الكبير من طبيعته الصامتة الميتة إلى مصاف الإنسانية العالية النبيلة ذات الحيوية والقيمة الوجودية العليا؛ فهو ملك يُدل عليه بوصفه لا

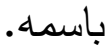
ومع صفة العظمة والسيادة على الجنوب الإسباني

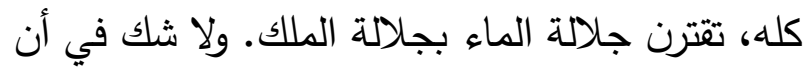
الجمع بين العظمتين، والإصرار على معنى الزعامة والفخامة إيماءة لفعل السيطرة والتحكم؛ فنهر الوادي الكبير هو مداد أنهار إسبانيا وكبيرها والروح المستحكمة على حياة الأرض وحياة الإنسان. ونلاحظ فكرة القوة والاندفاع والهيجان تؤطر صورة النهر في لوحة غونغورا، وهي ملائمة لفكرة القائد الفذ الذي يصول أمام خصومه بكل عنفوان وجسارة: عبر طريقك الملكي من البلاط الأندلسي 
الكبير في مسيرته الظافرة لا يتوقف عند حد الإمداد بعنصر الحياة، بل أيضا يقوم بتعهد الأرض والوطن فيحتويهما ويضمن طهارتهما. إنه دور وجودي خارق يمتد للإنسان والأرض التي يعيش عليها. وفي نص آخر يقول خوان ذي لا كويبا (1543$:{ }^{4}(1612$

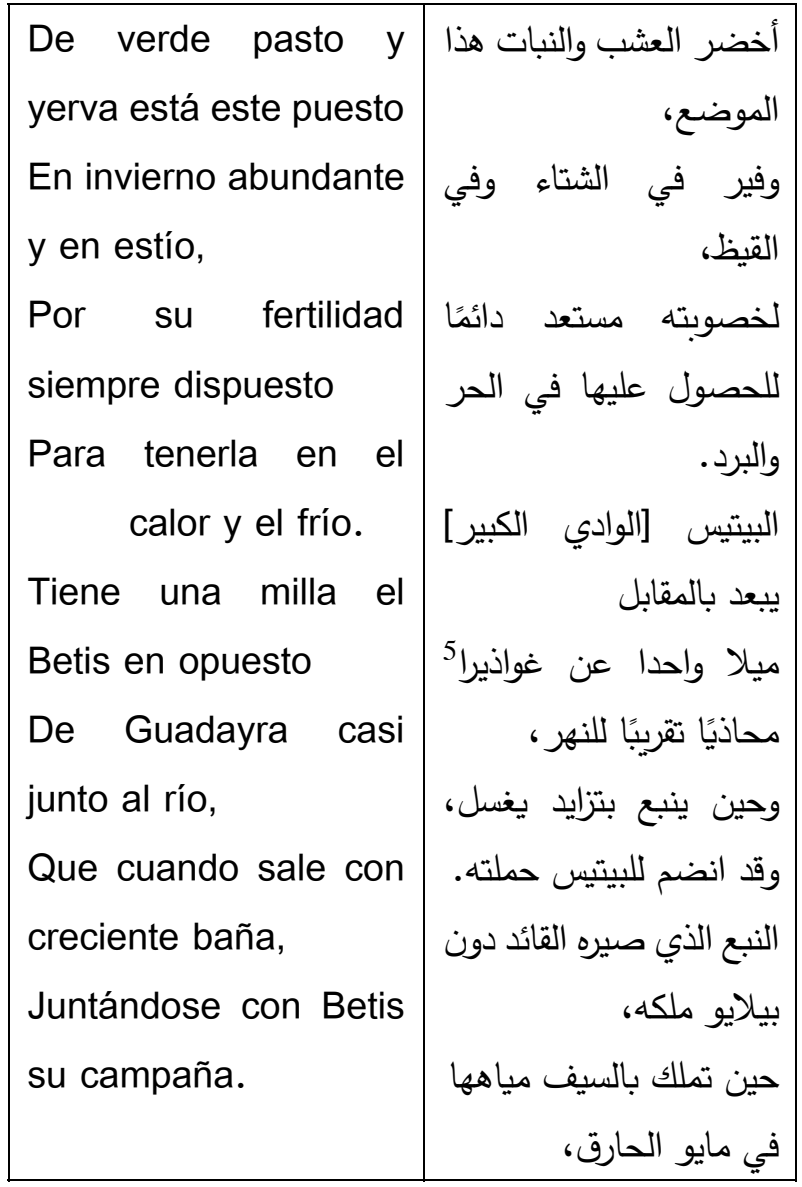

4 خوان ذي لاكويبا ذي غاروثا، شاعر وكاتب مسرحي إسباني ينتمي

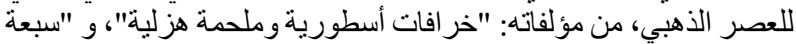

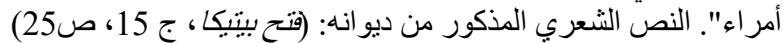
De la Cueva de Garoza, Juan. La Conquista de la Bética. Madrid: imprenta Real, 1795, t. XV, p.25.

بيتيكا من الأقاليم الرومانية القديمة، تنسب لنهر بيتيس وهو الاسم القديم

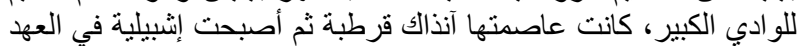

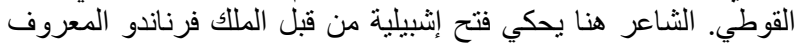
بالقديس في القرن الثالث عشر للميلاد. 5 أحد فروع نهر الوادي الكبير، يمر بإقليمي قادش و إثبيلية.
وسكون منه أيضًا؛ وداعة تحمله للجمود كالمرآة خدمة للعشاق، ليتشخص الوادي الكبير في الحالين على نحو أعم من مجرد عرضية الوصف للطبيعة. ويبدو أن القاسم المشترك لنظرة الثاعر الإسباني القديم للوادي الكبير هو مشهد العظمة والبأس الذي يقرنهـ في الذهن بسطوة الملك وشدته، وأحيانًا يأتي فردًا بصفة القوة والتعالي كما هو حال ألونسو خيرونمو ذي سالاس (1581-1635 م)1 الذي يقول عنه²:

\begin{tabular}{|c|c|}
\hline $\begin{array}{l}\text { En la patria de } \\
\text { Séneca, a quien } \\
\text { baña } \\
\text { Guadalquivir } \\
\text { soberbio y } \\
\text { arrogante, } \\
\text { Ciudad en los } \\
\text { ingenios felicísima } \\
\text { Que con razón } \\
\text { blasonan de sutiles }\end{array}$ & 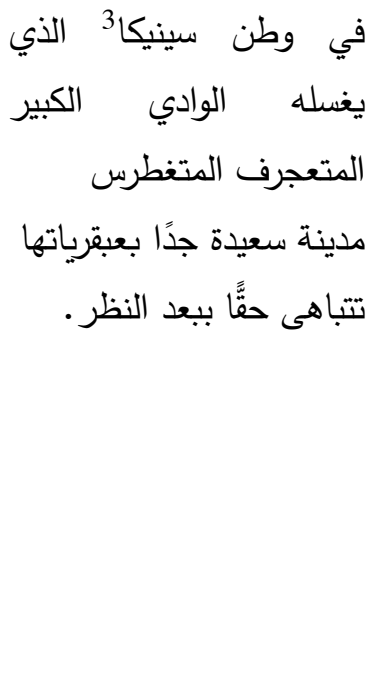 \\
\hline
\end{tabular}

الوادي الكبير هنا منعوت بالتعجرف والغطرسة، وهي غالبًا صفات تسوغها انطباعات القوة والغلبة التي يبثها في مشاعر الواقفين عليه والمتأملين له. إن الوادي

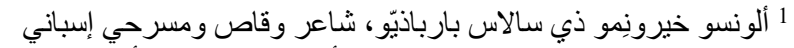

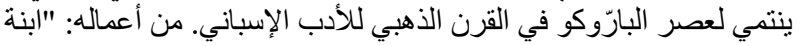

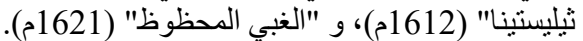

2 Jerónimo de Salas Barbadillo, Alonso. Obras de Alonso Jerónimo de Salas Barbadillo, Madrid: Tip. de la Revista de Archivos, 1907-09, p.133.

(خيرونِمو ذي سالاس بارباذيّو، ألونسو، أعمال ألونسو خيرونِمو ذي سالاس بارباذيّي ).

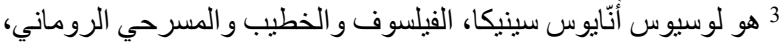

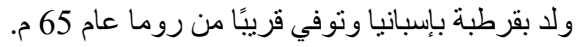


العتيقة حول ما يعنيه الوادي الكبير ، والمياه عمومًا، للشاعر ـ فلقد تعامل الأندلسي مع الماء بوصفه وسيلة

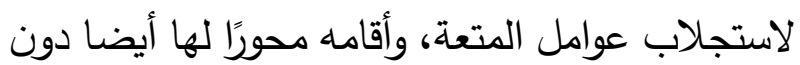
أن يترك ذلك في الثاعر أثرًا وجوديًا أو يستحيل ردزًا

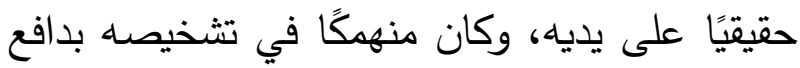
الانجذاب لثأن اللذة الحسية أكثر من الفكرية، في حين بدا الثاعر الإسباني القديم أكثر عمقًا من هذا

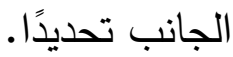
إن نهر الوادي الكبير الذي كان هامثًا عند الثاعر الأندلسي ولم يكن عنده مركز التجربة الشعرية، استحال لدى نظيره الإسباني القديم مركزًا ومنطلقًا؛ فهو محور الحديث وعليه ومنه تنهض الفكرة. لكن رغم ذلك، لم يحقق الثاعر الإسباني القديم التماهي الغائر؛ إذ كلما دنا من ذلك توقف فجأة على التخوم وكأنه يتهيب فكرة الترميز هذه أو يكتفي منها بالإرهاص والاقتراب. ولعل الثاعر الأندلسي في هذا الصدد كان لان لان

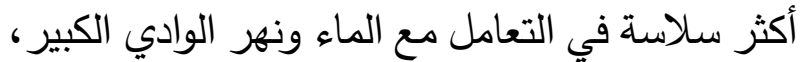
فالتجأ إليه لإضرام الفكرة المألوفة عند الأندلسيين كما لإلاهي أشرنا، ليكون النهر عنصرًا آخر يضاف لعناصر المتعة، فكان دوره بذلك مباشرًا وجليًا عكس الثاعر

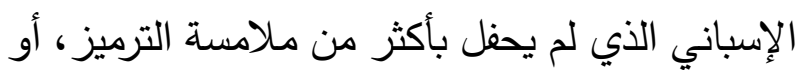
لم يكن على وعي كافٍ به على الأرجح. رمزية الوادي الكبير عند الثاعر الإسباني الحديث شهد العصر الحديث ثورة في مستوى العقل الأوروبي

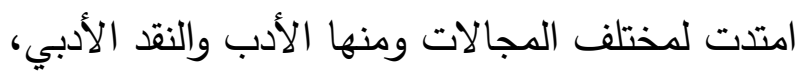

\begin{tabular}{|c|c|}
\hline $\begin{array}{l}\text { La fuente que el } \\
\text { Maestre D. Pelayo } \\
\text { Hizo suya, ganando } \\
\text { con la espada } \\
\text { El agua d ella en el } \\
\text { ardiente mayo, } \\
\text { Siéndole de los } \\
\text { bárbaros vedada. }\end{array}$ & جاعلًا إياها ممنوعة عن \\
\hline
\end{tabular}
هنا اتخذ الوادي الكبير بعدًا تاريخيًا مقرونًا بالقوة في

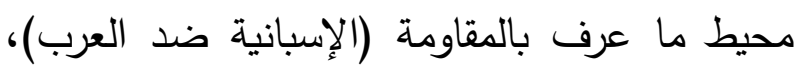
ممثلة برمزها التاريخي دون بيلايو (ت. 737 م)؛ وبحضور السيف الرامز للغلبة والقهر ليستقيم النهر دليلاً على المجابهة والبأس ضد الأعداء: النبع الذي صيره القائد دون بيلايو ملكه، حين تملك بالسيف مياهها في مايو الحارق جاعلًا إياها ممنوعة عن البرابرة. إن الاحتفاء بحيازة النهر وانتزاعه من العدو وحرمانه منه، إثارة إلى المحورية الوجودية له بالنسبة لإنسان إيبيريا الذي رمّز به للنصر والغلبة وحروب الاسترداد الثهيرة، وكأنا نعود للإنسان منذ نشأته وعلاقته بالماء الذي هو دليل الحياة ما يجعل الاستحواذ عليه هدفًا

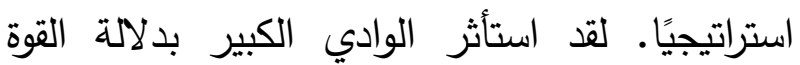
بوصفه مصدرًا لها أحيانًا وسبيلًا إليها أحيانًا أخرى. وخلاصة الكلام، أن واقع الثعر في هذه المرحلة يطرح تباينًا ملموسًا بين النسختين الأندلسية والإسبانية البذرة الأولى لما عرف بحروب الاسترداد الإسبانية. 
أثرًا بالغًا يجعله ينظر إليه بوصفه خلاصة تمثيل

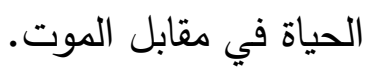

ولمفهومي الحياة والتجدد بوصفهما علامة متعلقة بنهر الوادي الكبير تمثيلات صغرى يمكن تلمسها في أثناء النصوص الثعرية محل الدراسة، وربما تجسدت، وفق ما يظهر من النصوص، في التالي:

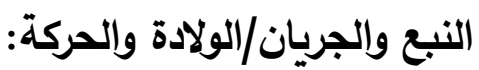
يكثف واقع الدراسة أن أول ما لفت عناية الثاعر الإسباني الحديث في نهر الوادي الكبير هو الانبثاق

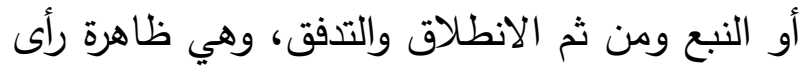
فيها الثاعر الإسباني أبعد من الحالة الطبيعية

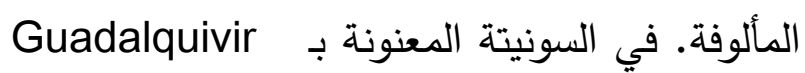
"الوادي en su nacimiento, en Cazorla الكبير، في ولادته في كاثورلا" للشاعرين الأخوين

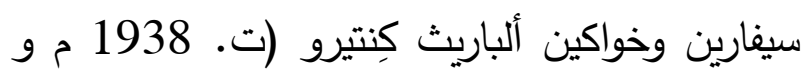
1944م)، الذي قيل إنه نقش في شاهد حجري؛ نقرأ

\begin{tabular}{|c|c|}
\hline $\begin{array}{l}\text { Detente aquí, viajero! } \\
\text { Entre estas peñas } \\
\text { Vace el que es y será } \\
\text { ey de los ríos, } \\
\text { Entre pinos gigantes y } \\
\text { ravíos, }\end{array}$ & 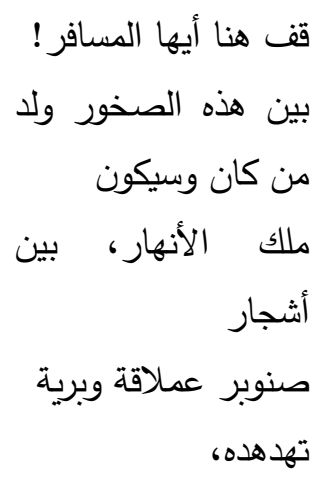 \\
\hline
\end{tabular}

${ }^{2}$ Eslava Galán, Juan, Viaje por el Guadalquivir y su historia, capítulo 8.

(إسلابا غالان، خوان، رحلة في الو ادي الكبير وتاريخه)
ولم تكن إسبانيا بمعزل عن تلك التطورات فهبت عليها رياح الرومانسية التي أذكت جمرة الثعور الوجداني حيال الموجودات، مرورًا بالبرناسية والواقعية والرمزية. كل ذلك انعكس على رؤية الثاعر الحديث للظواهر من حوله، وكانت الطبيعة مادة مناسبة لتجسيد مكتسباته حتى يمتزج الوجود بالإحساس في رموز

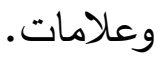
وبناء على استقراء عدد من النصوص الإسبانية التي قدرنا كفايتها لمنح صورة عامة لما يمثله نهر الوادي الكبير من رمزية في وجدان الثاعر الإسباني الحديث

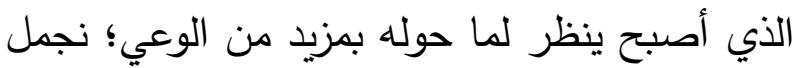

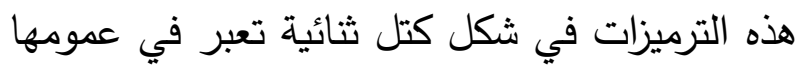
عن التماهي الكائن بين المادي والفكري: أولًا: الحياة والتجدد لا يخفى ما لعنصر الماء من تأثير فيزيائي يتعلق

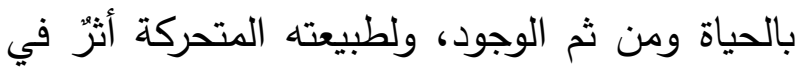
التعبير عن جوهر الحياة وعجلته الدائبة المتجددة. ولا شك أن نهر الوادي الكبير ، في جوهر طبيعته المتمثلة في ديناميكيته المترحلة ذات التمدد الجغرافي باتجاه المحطة الأخيرة (المحيط الأطلسي)، دون أن يكون

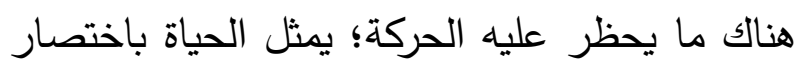
تاركًا في نفس الثاعر الإسباني الحديث والمعاصر لهاء لهاء

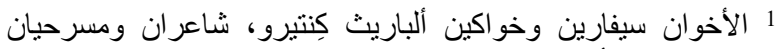

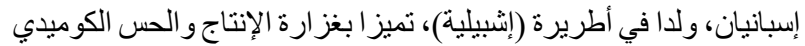

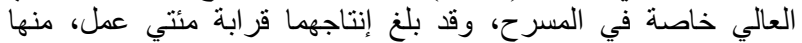
"الزهور"، و " العبقري السعيد". طبعت أعمالهما الكاملة في مدريد في العي 
يبدو أن صورة الوادي الكبير ، الملك المتوج على سائر الأنهار، من موروثات الشعر الإسباني منذ القديم كما شهدنا عند لويس ذي غونغورا على سبيل المثال، ما يعني الشعور به وجودًا حيًا تستمد منه الجلالة ويستجلب الإقدام. وانبثاق هذه الحياة الفخمة وانبعاثها من العدم لا ينبغي أن يكون حدثًا اعتياديًا بل مختلفًا وتاريخيًا، لذا وصف الثاعر ولادة النهر بالصعبة من خلال الإشارة إلى الصخور. النبع أو الظهور في النص معادل للولادة التي هي شرارة الحياة الأولى وإيذانها الرسمي، ولا شك أن تصاعد المياه من بين الصخور المشقوقة والمختبئة في الزوايا البينية تمثل لبزوغ الطفل من موضع الولادة المختبئ في جسد المرأة، وهو خروج بتطلع للحياة وتوثب إليها، كما هو حال اندفاع الماء من زوايا المكان: بين هذه الصخور ولد من كان وسيكون ملك الأنهار إن مقابلة النبع المائي بالولادة وبالتالي نجوم الحياة وانبثاقها، خيال منيف وتشخيص ناضت، جعل الفكرة ولادة إنسانية فاخرة حين قرن النهر بالملك. وهذا الوصف بالملك متصل بحديث ضمني يشخص كل الأنهار التي تتبع كما يخرج الصغير من رحم أمه فإذا هي كالناس في الحياة والحركة، وفي التفاوت في القيمة، تحفها العناية كالولدان مع حظوة خاصة للوادي الكبير: بين أشجار الصنوبر العملاقة والبرية التي تهدهده

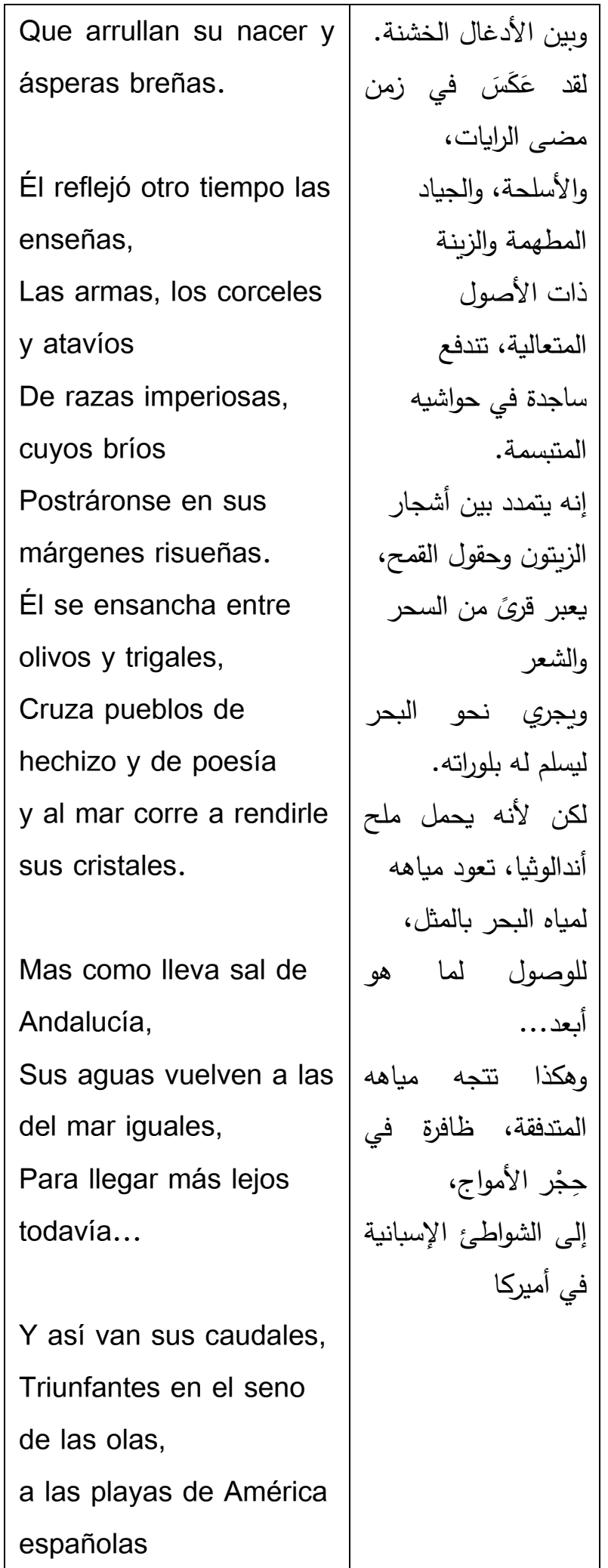




\begin{tabular}{|c|c|}
\hline $\begin{array}{l}\text { ¡Oh Guadalquivir! } \\
\text { Te vi en Cazorla } \\
\text { nacer; } \\
\text { hoy, en Sanlúcar } \\
\text { morir. } \\
\text { Un borbollón de } \\
\text { agua clara, } \\
\text { debajo de un pino } \\
\text { verde, } \\
\text { eras tú, iqué bien } \\
\text { sonabas! } \\
\text { Como yo, cerca del } \\
\text { mar, } \\
\text { río de barro salobre, } \\
\text { ¿sueñas con tu } \\
\text { manantial? }\end{array}$ & 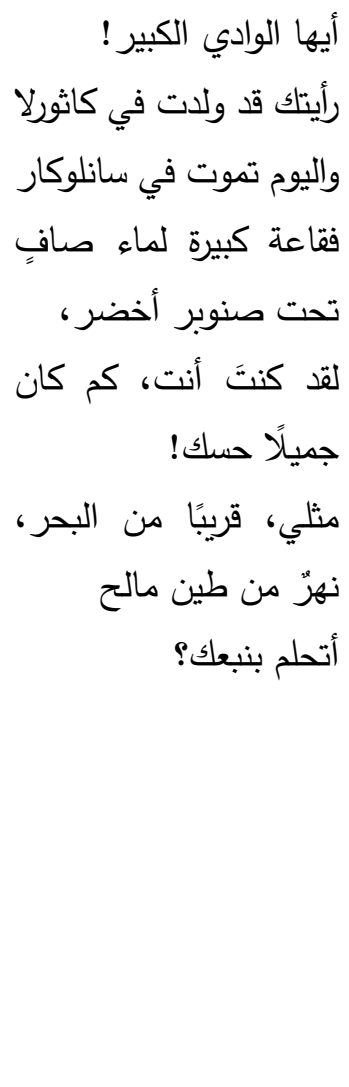 \\
\hline
\end{tabular}

لقد صادق الثاعر على صفة البشرية الممنوحة للنهر وهي الحياة في البدء والنهاية، وعبّر بالولادة عن نبع النهر واصلًا ذلك بالمكان بوصفه هوية عليه كما يقيد المولود في الأوراق الرسمية بالساعة ومكان الولادة. وفي الإشارة هنا إلى البعد الصوتي ربط بالحياة (كم كان جميلً حسك!)؛ فالنهر يهب التماعة التدفق والحركة وهي فيه دليل الوجود كما هي في البشر تمامًا؛ إذ الحركة هي الحياة والسكون علامة الموت، والحركة جمال لما تتضمنه من التجدد؛ فكل جديد

\footnotetext{
${ }^{2}$ Machado Ruiz, Antonio. Nuevas canciones. Poesías completas, España:

Rincon Castellano 1997 - 2011, p. 33 (edición digital).
} (ماتثادو، أنطونيو ، قصائد جديدة. قصائد كاملة، "نشرة إلكترونية").
ولأن الحديث مشمول بحس العظمة والظفر ، نرى الثاعر يختار الجريان لوصف حركة النهر ، وهو ليس هروبًا كما سنرى عند غيره، بل علامة الحيوية والتوثب والإقدام. كما أنه اندفاع لا يعرف أضيق الطريق كما هو شأن الحيوات متواضعة القدرات، بل تدفق في مسالك رحبة من الحقيقة والخيال " الشعر والسحر "، حتى ليشمل الأمر ما هو أبعد من شواطئ إسبانيا في إسبانيا لتمتذ صورتها لأمريكا اللاتينية، في إثارة لاتساع الرقعة الملكية الظافرة التي اتخذ الوادي الكبير معادلً لها: إنه يتمدد بين أشجار الزيتون وحقول القهح، يعبر قرئً من السحر والثعر ويجري نحو البحر ليسلم له بلوراته. لكن لأنه يحمل ملح أندالوثيا، تعود مياهه

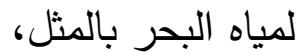
للوصول لما هو أبعد.... وهكذا تتجه مياهد المتدفقة، ظافرة في حِجْر الأمواج، إلى الثواطئ الإسبانية في أميركا وهذا أنطونيو ماتثادو (1875م-1939م) في إحدى الإنى مقطوعاته يدور على الفكرة ذاتها:

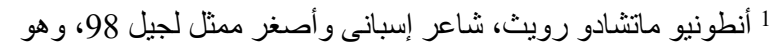

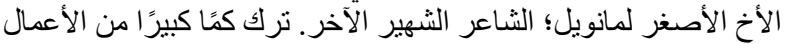

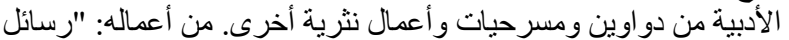
إلى بيلار ، و "الرجل الذي مات في الحرب". 


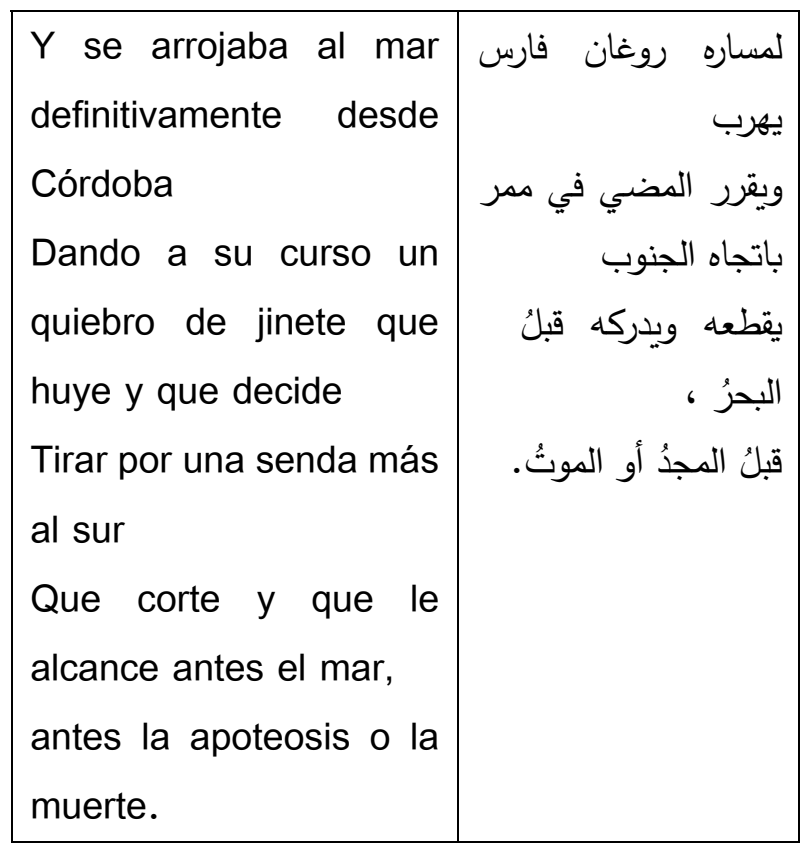

رغم ما يحيط هذا النص والذي يليه من شعور قاتم، زاوجت الثاعرة بين النهر والحياة عن طريق الإشارة إلى حتمية العبور والانتقال: (هذا النهر العابر)، دلالة على الحيوية المحتدمة في المكان (قرطبة وإشبيلية)، في صفة إنسانية معبرة، وكأنه رحالة لا يمل من التنقل والعبور بالمواضع التي جاءت هي الأخرى مفعمة بالحياة: "روح قرطبة وإشبيلية"، في تفاعل مباشر بين أجزاء الطبيعة تحكي تفاعل الإنسان الحي بها. والواقع أن النص بعلاماته الحيوية يعاني ضربًا من الحركة المتألمة، فهو متدفق على مضض بسبب حمله "الدم والتنهيدات"، وهي دلالات اعتلال في الحياة لكنها لا تعفي النهر من لازمة التدفق الطبيعي ولا تعيقه

لمجلتي: "إنشبيلية" و "شعر"، لها عدة دواوين، منها: "مراثي الوادي الكبير"، و "بئر يعقوب" و"ن و "نسائم الحب". 3 "Poema para una comparecencia en la Fiesta Mundial de la Poesía Árabe (Sevilla para Córdoba)" en Fiesta de la Poesía Árabe. IX Centenario de Aben Házam, 12 al 18 de mayo. Córdoba, 1963.

(قصيدة للمشاركة في حفلة عالمية ليوم الثُعر العربي، المئوية التاسعة لابن
نضِرٌ في العين وفي سائر الحواس، وجمال الحياة عمومًا مرده خطابها للحواس خلاف الموت والسكون والجمود. ولافت أن ندرك أن أنطونيو ماتثادو المنتمي لجيل 98 قد عرف بتأثره بهنري برغسون، الفيلسوف ولج الفرنسي الشهير (1859-1941م) الذي توفر في فلسفته على أفكار الديمومة والتوثب والتجدد في نظرته للوجود والإنسان، ومن هنا نفهم رمزية الوادي الكبير عند أنطونيو ماتشادو في كونه (أي النهر) خير من يجسد هذه الفكرة الفلسفية الوجودية. أما خير من يمثل هذه الفكرة من الثعراء الإسبان المحدثين فأراها الثاعرة الإشبيلية ماريّا ذي لوس رييس فوينتس (1927- 2010 م)2، فمن يتأمل شعرها في هذا النهر النابض في مدينتها ومن جوارها، يدرك عمقًا كبيرًا في التصورات وقدرة عالية على الجمع بين وجودية النهر ووجودية الإنسان 3:

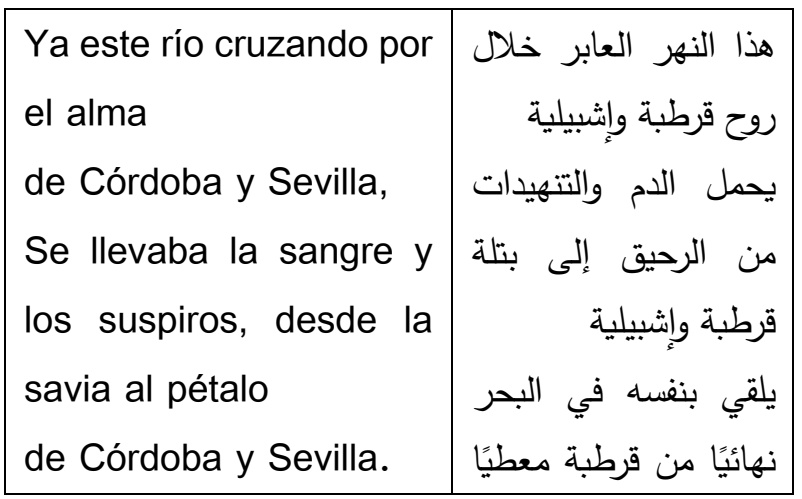
1 عن تأثير بير غسون في أنطو نيو ماتثنادو؛ انظر مثلًا: Glendinning Nigel: "The philosophy of Henri Bergson in the poetry of Antonio Machado", Revue de littérature comparée, 36 (1962), pp. 50-70.

(نيجيل، غليندينيخ، "أثر فلسفة هنري بيرغسون في شعر أنطونيو

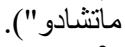
2 ماريا ذي لوس رييس فوينتس، شاعرة إسبانية ولات بمدينة إثبيلية، تنتمي للأكاديميات الملكية بقادش و إثبيلية ومالقة وقرطبة، وتعد مؤسسة بنسية 


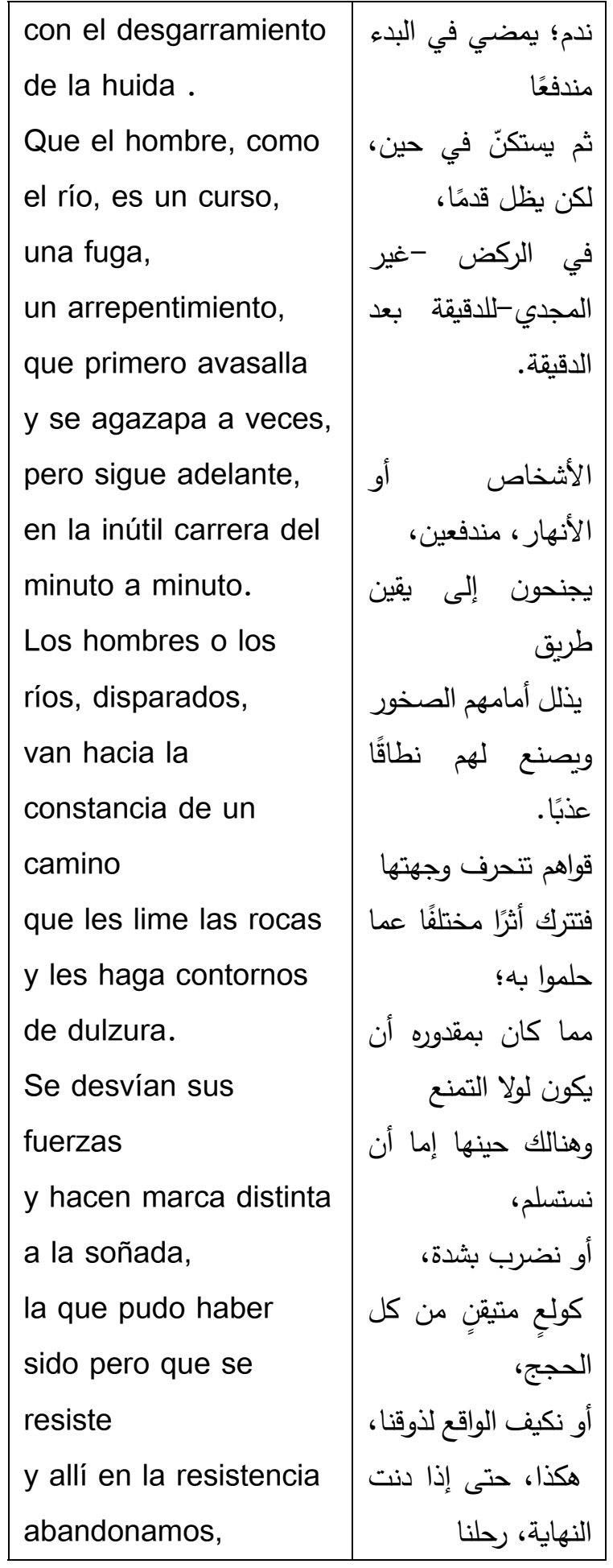

(فوينتيس، ماريا ذي لوس رييس. مر اثي الو ادي الكبير).
عنها، كما الاعتلال غير مانع للحياة بالضرورة، فهي ماضية للأمام قطعًا. وعبارات مثل "يلقي"، "هرولة"، "يهرب"، "المضي"، توثق عملية التدفق بغض النظر عما يعتريها من خلل، وربما كان التعبير ب"هرولة"، و "هرب" ممعنة في جعل الحركة والحياة هنا واجبة رغم الإشكالات والمخاطر التي تكون سببًا في المقاومة أحيانا؛ إذ ربما كان الهروب مقاومة للخطر واستدامة للحياة.

وفي نص آخر بعنوان "النهر" نجدها أكثر جرأة في ترميز الحياة والموت منطلقة أيضًا من الوادي الكبير؛ تقول

\begin{tabular}{|c|c|}
\hline $\begin{array}{l}\text { brazc } \\
\text { con } \\
\text { fin: } \\
\text { ejem }\end{array}$ & 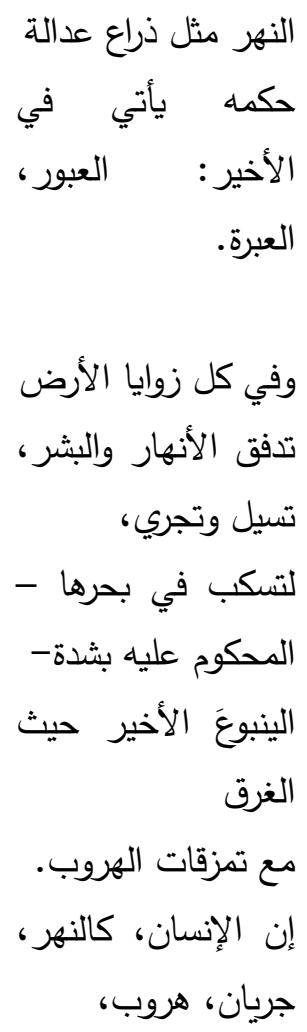 \\
\hline
\end{tabular}

${ }^{1}$ Fuentes, María de los Reyes. Elegías del Uad el-kebir. Excmo, Sevilla: Ayuntamiento, 1961, p. 17 (poema El Río). 


\begin{tabular}{|c|c|}
\hline $\begin{array}{l}\text { columna } \\
\text { que busca la } \\
\text { sentencia del Océano, } \\
\text { la meta irremediable } \\
\text { de donde han de } \\
\text { brotar, ay sí, las } \\
\text { nuevas aguas, } \\
\text { porque el río delata su }\end{array}$ & 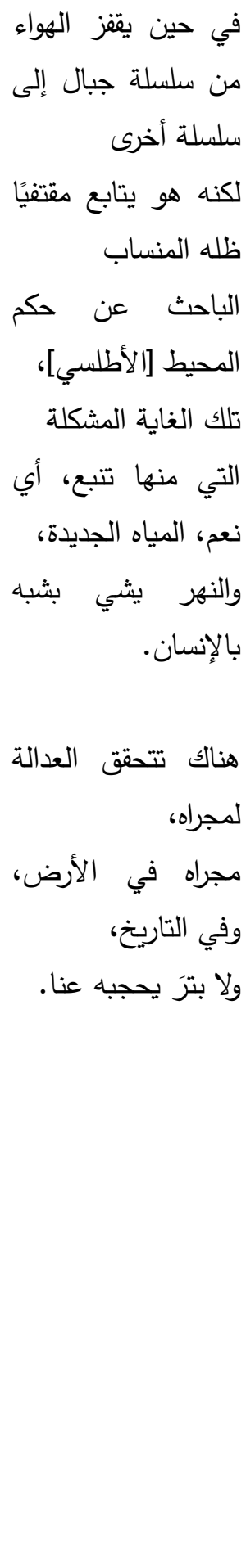 \\
\hline
\end{tabular}

يتقاطع هذا النص مع سابقه بوصفهما تأملات راسخة في نهر الوادي الكبير، تجمعه بالإنسان تحديدًا. في

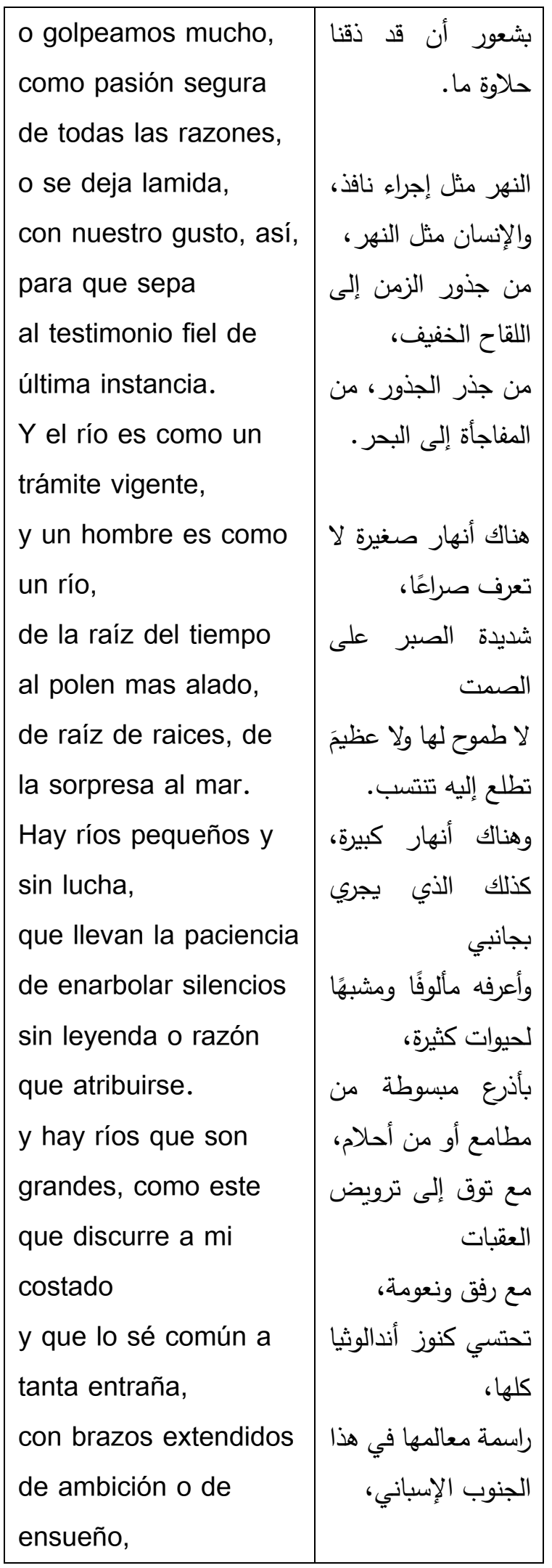


لقد آخت الثاعرة بين الطبيعة والإنسان، ولعل هذه الطبيعة الممثلة بالنهر، قد حقتت المشابهة الوجودية بالإنسان وبالحياة أكثر من غيرها حيث هيئة الحياة تتجسد في الجريان والتدفق: "تدفق، تسيل، تجري..."، وهي أبرز خصائص المياه الحية (إن صح التعبير) إزاء المياه الراكدة الميتة. وتمعن الثاعرة في تطلب مشاهد الشراكة في الحياة بين النهر والإنسان: إن الإنسان، كالنهر، جريان، هروب، ندم؛ يمضي في البدء مندفعًا ثم يستكن في حين، لكن يظل قدمًا، في الركض -غير المجدي-للدقيقة بعد الدقيقة. انطلاقًا من الخصائص الوجودية: النبع والحركة، تتناسل سمات أخرى مشتركة بين النهر والإنسان عن طريق المقاربة بينهما بالتوظيف الدقيق للتشخيص؛ فالهروب ثم الندم، صفات بشرية، فلا يندم إلا البشر ذوو الحياة وليس في الأنهار إلا من قبيل المجاز الدقيق. وفعل الندم في النص جاء مسبوقًا بعمل غير مرغوب؛ فلقد عطفته الشاعرة على فعل الهروب وجعلت هذه الصفات أصيلة في النهر على اعتبار أنه المشبه به والإنسان المشبه، وهو قلب للمألوف، لتتأكد المشاركة التامة بينهما في السعادة والبؤس، وانظر لتعبيرها بـ "تمضي" و "الركض" وقوة التلازم مع صفة الحياة المرتهنة بالحركة، وهي حركة دائبة في جوهرها:

(مارتينيث أورتيغا، كارمن إيلينا. شعر ماريا ذي لوس رييس فوينتيس. رسالة دكتور اه).
النص السابق تعالق النهر مع الحياة يجمعهما التدفق والحركة المصورة بـ "العبور": "هذا النهر العابر خلال روح قرطبة وإشبيلية". وهنا النهر ذراع العدالة الذي يمضي نافذًا بقوة ليصل منتهاه ويدرك مبتغاه، كالحياة في مصيرها النافذ المدلول عليه بالحركة ذات المبتدأ والنهاية: النهر مثل ذراع عدالة حكمه يأتي في الأخير : العبور ، العبرة. في هذا الموضع لمحة طريفة تدفعنا لتفهم استهلال الثاعرة نصها متكئة على مصطلح "ذراع عدالة"؛ فقد درست القانون في مدينتها إشبيلية، الأمر الذي أتاح لها النظر إلى الوجود بوصفه قوانين نافذة غايتها العدل، وقد علقت إحدى الدارسات لشعر الثاعرة على التفاتتها للقانون بالقول إنه: "ولد من رغبة في العدالة" . فبالرغم من تباين الأحكام النافذة في الناس والحيوات بما يوحي باللاعدالة، فلا شك من سيادة عدل الموت الذي هو غاية الإنسان ومصيره، لا يتملق أحدًا ولا يفلت منه كائن حي. والوادي الكبير يضارع الإنسان في جريانه في الأرض وديمومة ركضه في الزمن وراء مطامعه وأحلامه، ولذا زاوجت القصيدة بين حديث النهر وحديث البشر :

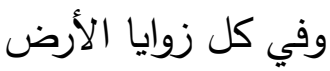
تدفق الأنهار والبشر، تسيل وتجري،

${ }^{1}$ Martínez Ortega, Carmen Elena, La obra poética de María de los Reyes Fuentes, tesis doctoral, Sevilla, 2011, p. 223. 
هيراقليديس: "أنت لا تسبح في النهر مرتين"، في معرض تأكيده على فكرة التبدل والتجدد، وإلى الفرنسي "برغسون" في تأملاته عن الوجود الواعي، الذي يرى

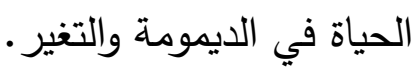
وإمعانا من الثاعرة الإثبيلية في الدوران على موضوع التدفق والجريان/الولادة والحركة، نراها تحدثا عن الإنائ النهز الإنسان الذي "يحتسي كنوز أندلوثيا كلها"، وفي تلانيان

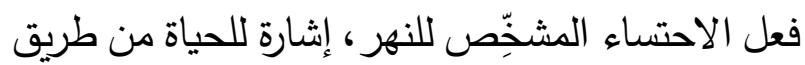
الماء الذي هو سببها حين يتدفق ويجري. وهنا مفارقة لطيفة مردها ازدواجية الدلالة؛ فالماء -الذي يحتسي

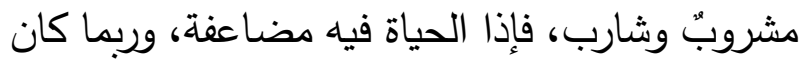
هذا شرحًا لفكرة الأنهار العظيمة والكبيرة، ولا شك أن أن أنان نهز الوادي الكبير كذلك، وفكرة احتساء الكنوز إيحاء بفخامة هذا النهر وقيمته؛ فلا يقتات إلا على عظير.

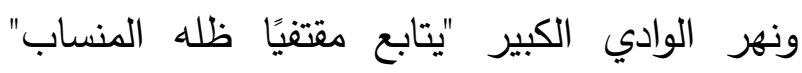
فجريانه دائم وحياته أبدية، كالإنسان الذي يمشي في الإي مناكب الأرض لغير وجهة يقينية-وهذا ما أرادته الثاعرة، الإنسان في مشيه على غير هدى في هذه

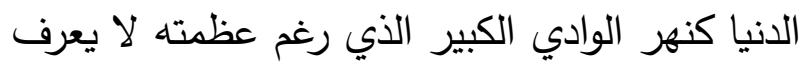

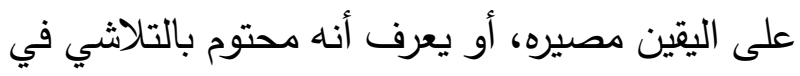
المحيط فيسير على هدي ظله المظظِلّ، كالإنسان القوي المندفع باستسلام إلى النهاية. إنه الإثكال الوجودي الأزلي الذي يلح بسؤاله على الإنسان سفي الني شكل النهر -عن جدوى الحياة وقيمة الوجود، وهنا الآنسان تتراءى تثاؤمية شوبنهور وعدمية نيتشة:

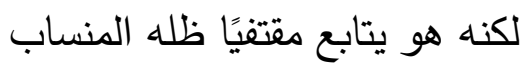

"الدقيقة بعد الدقيقة" ينتابها بعض السكون الذي لا يضر بالصفة اللازمة ابتاءًً، وهي صفة الحياة.

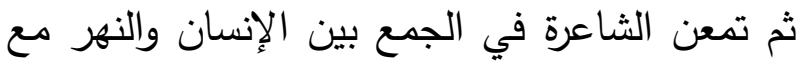

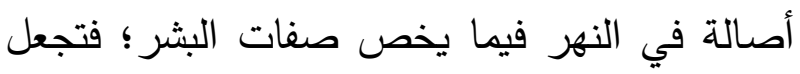
لكليهما قيمة تتوقف على مقدار الهمة والتطلع؛ فكما أن هناك بشرًا كبارًا وعظماء فهناك أنهار عظيمة النهار وكبيرة والعكس صحيح. إن النبع والجريان أو الولادة

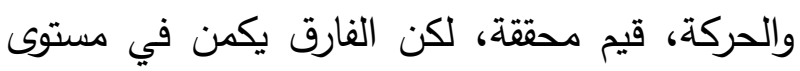
التحقق ودرجته المرتبط أسائًا بدرجة الطموح والتطلح. إنها صفات بشرية تعيدنا للتشخيص الجامع بين النهر والإنسان بعد تجاوز مرحلة الوجود والفعل، وكما أن النيان الإنسان متفاوت الهمة والتطلع كنلك الأنهار بعضها واسع المطامع والتطلعات فيكون كبيرًا كالوادي الكبير الائران

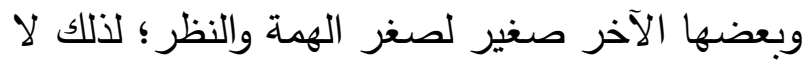
تعبأ بالإنسان الصغير/الأنهار الصغيرة، فالحياة هناك لكئك محدودة القيمة والإضافة: هناك أنهار صغيرة لا تعرف صراعًا،

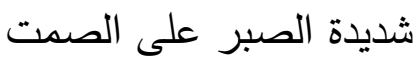
لا طموح لها ولا عظيمَ تطلع إليه تنسب

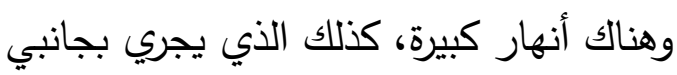
وأعرفه مألوفًا ومشبهًا لحيوات كثيرة، بأذرع مبسوطة من مطامع أو من أحلام

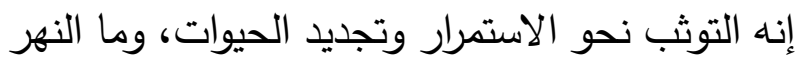

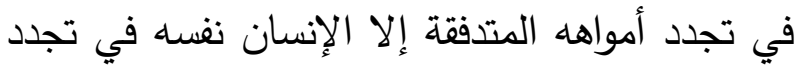

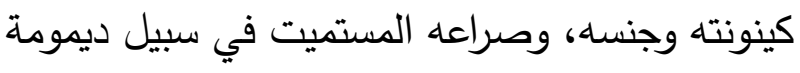
وجوده وتدفقه. هذا الهشهذ يعيد الذاكرة لعبارة اليوناني 


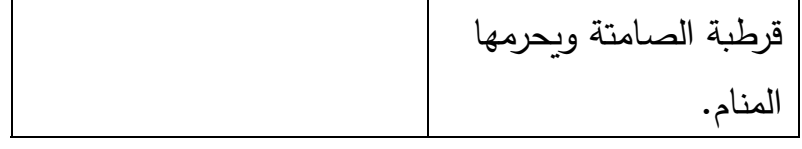

ثنائية النبع والجريان تطل من جديد تمثيلً للجانب الوجودي البشري المحيل إلى الحياة وانبعاثها؛ فقد زاوج الثاعر بين ضوء الفجر والماء، وجعل الحدث ولادة والوادي الكبير الأم أو القابلة التي تمنح الحياة أو تجري لتبشر بها، ويظل النور كالمؤشر أو القرينة لهذه الحياة يشع بهدوء على جوار المدينة (قرطبة)، وكأنه يداعبها ويوقظها، وجميعها أفعال الكائن الحي المتوثب للحياة مقابل الطرف الآخر الموصوف بالسكون؛ فإذا النهر الكبير رمز الحياة وتولدها وحاضن النور والحيويـة.

وفي مناسبة أخرى، في قصيدة رثائية يقول ريكاردو مولينا أيضًا2

Amanece en las calles. Córdoba se despierta. Ya es de día. Te amo. Ya van camino del río los areneros con sus palas, sus asnos.

El invierno se va. La niebla se disuelve en torno de los álamos. Crecido viene el río como mi corazón. Tu recuerdo desborda como el río mi vida inundándola toda con sus aguas violentas donde flotan almiares,

${ }^{2}$ Molina, Ricardo. Aún es Córdoba Bella. Antología poética. Selección y prólogo: Carlos Clementson, España: Junta de Andalucía, 2017, p. 52. (مولينا، ريكاردو. لا نز ال قرطبة جميلة. مختار ات شعرية).
الباحث عن حكم المحيط [الأطلسي]، ثم تأتي لوحة الختام تلخيصًا لعموم الفكرة: تلك الغاية المشكلة التي منها تتبع، أي نعم، المياه الجديدة، والنهر يشي بشبه بالإنسان هناك تتحقق العدالة لمجراه،

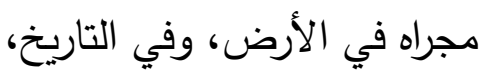
ولا بترَ يحجبه عنا لئا لقد تماهي الوادي الكبير بالإنسان تمامًا؛ فالنبع الحياة، لماءك

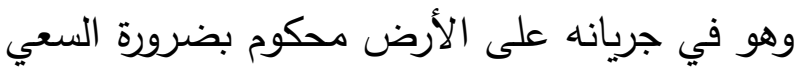
ومواجهة النهاية المحتومة التي ينطوي فيها البشر لهردي جميعًا وهذه هي العدالة التامة، وكما يرحل الإنسان عبر التاريخ ويشكّله، كذلك نهر الوادي الكبير الذي هـي يتقيد في سجل التاريخ ثم لا يمكن لأي قوة أن تمنع اتصاله بالحاضر والمستقبل، تمامًا كما هو الإنسان

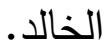
ويقول ريكاردو مولينا (1968-1916م)1': Al Alba la luz nace del agua. Guadalquivir la trae pálida.

Empieza siendo un beso, un que acaricia y desvela el alma de Córdoba dormida, de Córdoba callada.

يديد يدأ قيأ قُبلةً

1 ريكاردو أنطونيو مولينا، شاعر إسبانيا، كان عضوًا في مجلة كانتيكو Cántico

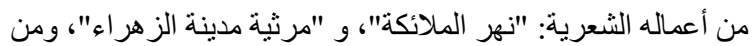
مؤلفاته النثرية: "أسر ار فن الفلامنكو ، و "الوظيفة الاجتماعية للثشعر". 
ذكرى الحياة كالنهر، والنهر لا يكف عن التدفق مثل الحياة التي لا تتوقف، والنهر كالحياة يحمل على مياهه الجمادات والحيوانات ويندفع بها بقوة كالحياة التي تتسع لكل ذلك وتمضي به قُدُمًا نحو مصير

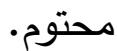
ويقول أنطونيو ماتشادو

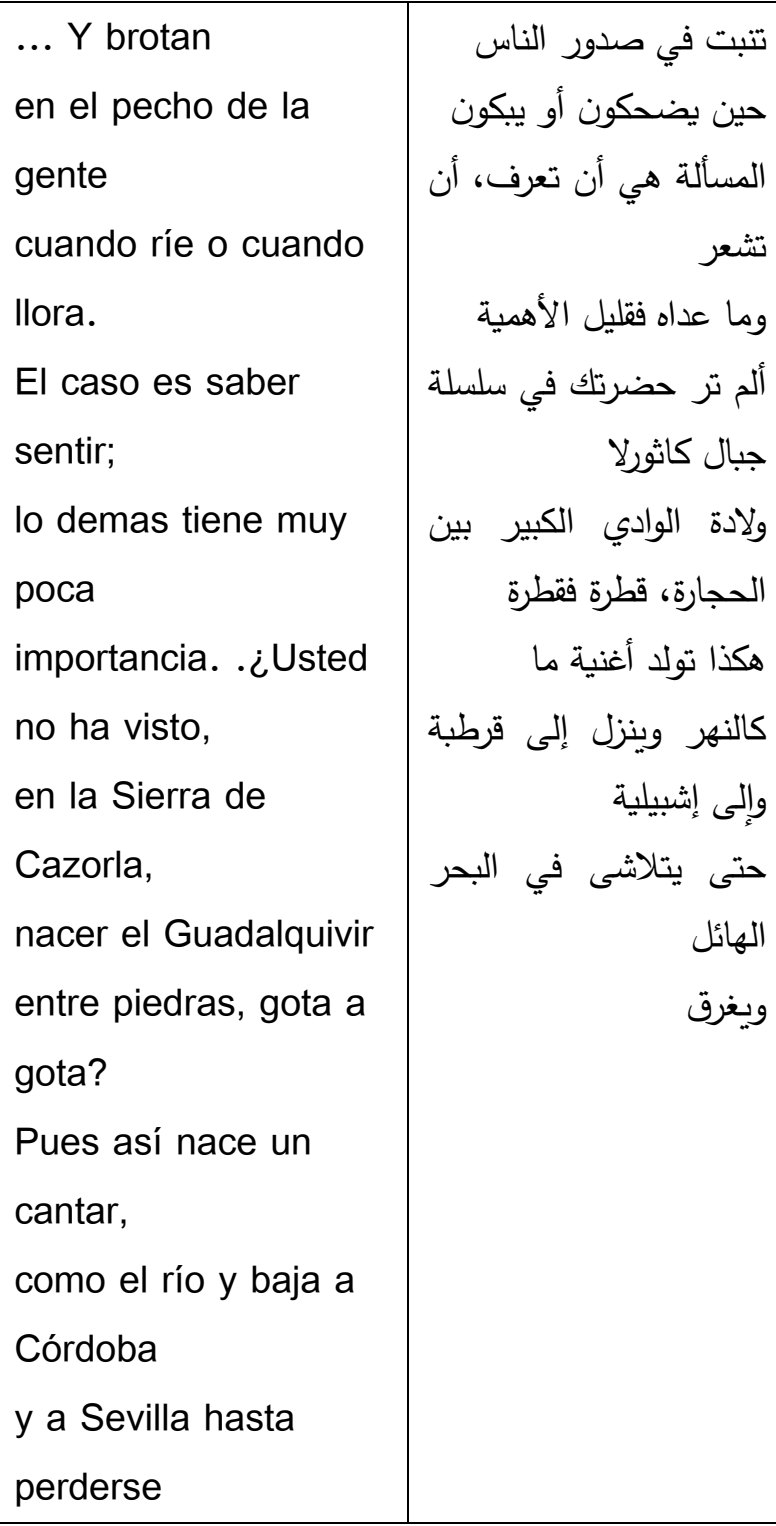

(ماتثادو، مانويل و أنطونيو، الأعمال الكاملة).

\begin{tabular}{|c|c|}
\hline $\begin{array}{l}\text { animales que aúllan, } \\
\text { negros troncos de } \\
\text { árboles y despojos y } \\
\text { ruedas. }\end{array}$ & 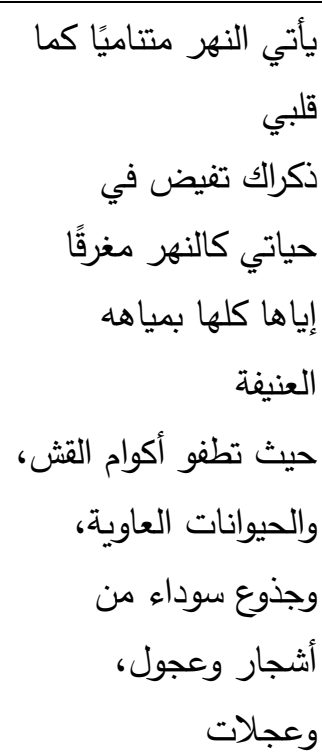 \\
\hline
\end{tabular}

لاحظ تعلق نهر الوادي الكبير بالحياة وتجددها معه؛ فما أن تشرق الثمس وتبدأ الحياة في التدفق من جديد حتى يأتي على ذكر الوادي الكبير بوصفه معادل ذلك كله؛ فالحياة تتبجس في اتجاهه حينما يتوجه إليه بائعو الرمل بأدواتهم ودوابهم بعد أن أذن لهم نور الصباح بالتدفق من جديد. وهو بدوره يتدفق متزايدًا، والفعل (crecer) قصده الثاعر هنا، وهو فعل التطور في الحياة والتدفق فيها انطلاقا من نقطة الولادة أو البداية التي ناب عن الرمز لها نور الصباح الذي يعد المكافئ للنهر • تأمل أيضًا كيف يرتبط نهر الوادي الكبير بالحياة مرة أخرى في آخر القطعة الشعرية هنا، فإذا كل منهما لازمة للآخر : ذكراك تفيض في حياتي كالنهر

\footnotetext{
${ }^{1}$ Machado, Manuel y Antonio. Obras Completas. Madrid: Plenitud, 1957, $3^{\circ}$ ed., pp. 458, 479.
} 


\section{- النهاية والتلاشي/الموت}

لا تكاد تقرأ شعرًا لأنطونيو ماتثادو مثلًا، موضوعها نهر الوادي الكبير إلا ويستجلب له حديث البحر (المحيط الأطلسي)، راهزًا به للنهاية، مستثرًا واقعية

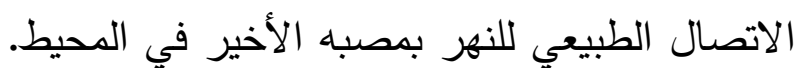
وقد جرب ماتثادو في هذا نوعًا من التأثر والتأثير؛ فاستعاد الثاعر الثهير خورخي مانريكي (1440 1479 م)1 الذي جرى الربط بينه وبين أبي البقاء

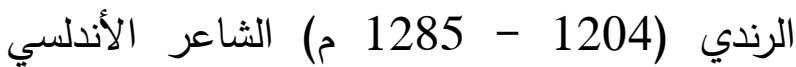
الثهير، من جهة تأثر مانريكي في مرثيته الثهيرة

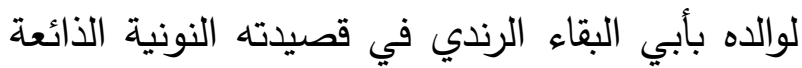

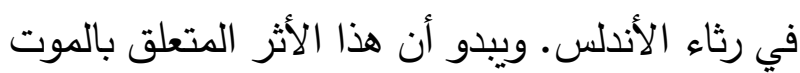
هو ما يجمع كلا الثاعرين، ويظل الوادي الكبير في استهلال مجراه وختامه خير من يمثل الإنسان في طلوعه للحياة ثم أفول نجمه نهاية الأمر. يقول خورخي مانريكي في مرثيته لوالده²

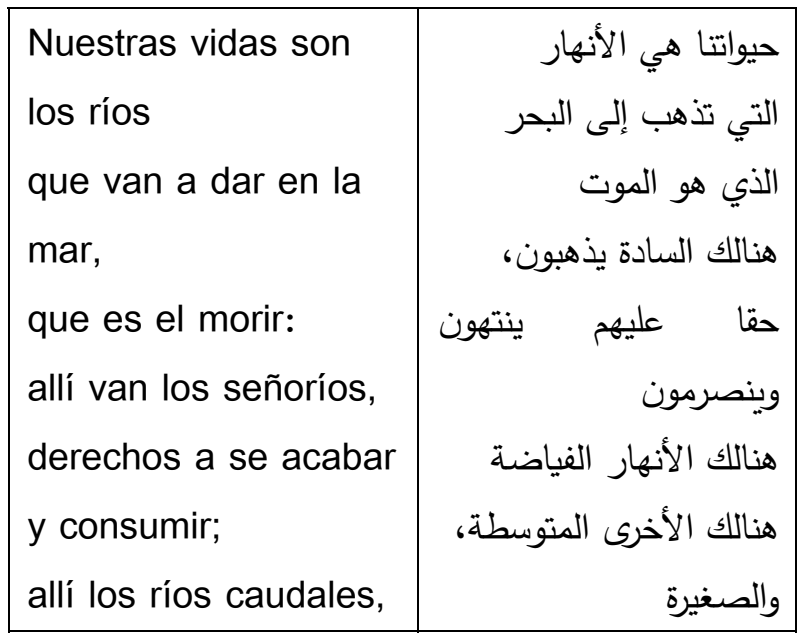

${ }^{2}$ Manrique, Jorge. Coplas a la muerte de su padre y otros poemas, Sevilla: Alfar, 2014; $2^{\circ}$ edición, Copla III. (مانريكي، خورخي، مقطو عات عن موت و الده وقصائد أخرى،

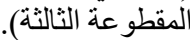

\section{en la mar tan grande} y honda.

في النص يتمثل أنطونيو ماتثادو فعل الولادة ليتصدر استدعاءه لنهر الوادي الكبير الذي ينبع من بين الحجارة كما ينجم المولود من بين المرأة. هذه المرأة كائن جلد صامد أمام الخروج المؤلم للحياة الجديدة، كالحجارة تظل جامدة رغم انبعاث المياه من خلالها. إنه انبعاث لطيف وهادئ في أوله، يجمع النهر والإنسان؛ فتولد الماء يبدأ "قطرة فتطرة" والولادة خروج حذر لحياة تدب دبيبًا ثم تجري جريانا وهي صفة الماء تمامًا. والفعل الهادئ في النص مشبه أيضًا بمطالع الأغنيات التي يعبر عنها بالولادة "هكذا تولد أغنية ما"، فبدايات الأغاني التي يعنيها تتولد بهدوء من فكرة لشعر ولحن أولي، وربما انطلقت بهدوء يسري في الروح، ولاحظ أنه آثر تصدير هذا الجزء من المقطوعة بالفعل (brotar/ينبت)، في دلالة على تولد سلس كبزوغ النبتة واسترسالها بهدوء نحو السماء. إنها ولادة غير صاخبة، رزينة جدًا تتلوها حركة متأنية كتأني الشخص الذي يهبط من مرتفع "وينزل إلى قرطبة وإلى إشبيلية"، وهذا هبوط مكاني جعل الولادة إنزالًا وجعل قرطبة وإشبيلية بمثابة الأرض التي ينزل عليها المولود بهدوء ثم يدب فيها مستغرقًا عمره حتى النهاية أو الوفاة التي أشار لها الثاعر، وسنتتاولها في قادم السطور .

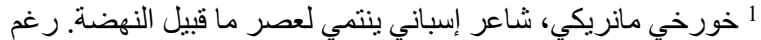

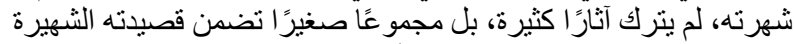

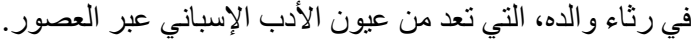




\begin{tabular}{|l|rr|}
\hline por donde se va, & بين & أشجار \\
entre naranjos de oro, & & \\
Guadalquivir a la mar! & & \\
\hline
\end{tabular}

يتهادى إلى ذهن المتلقي عند التقاطه لهذه الأبيات موقف الجنازة ومراسم العزاء، ويرمز الوادي الكبير للإنسان حال تشييعه محمولًا في تابوته إلى مثواه الأرضي الأخير، وقد حفت بالنهر الثمرات والأشجار كأنما هو محفل توديع مهيب، ثم رمز بالبحر (المحيط الأطلسي) للنهاية أو القبر ، حيث يتبدد الوادي الكبير كما الإنسان الذي يثوي ثم يتحلل في حفرته الصغيرة. إنها تظاهرة نحو النهاية والموت، يمضي النهر لمصبه الأخير مضي الإنسان لقدره المحتوم، ومادام المصير هو القبر أو البحر فلا يهم إن وصل إليه حيًا أو ميتًا: ومن قصيدة له سبقت الإشارة إليها في الأعلى يقول أيضًا أيها الوادي الكبير ! رأيتك قد ولدت في كاثورلا واليوم تموت في سانلوكار

فقاعة كبيرة لماء صافٍ تحت صنوبر أخضر ، لقد كنتَ أنت، كم كان جميلً حسك! مثلي، قريبًا من البحر ، نهرٌ من طين مالح أتحلم بنبعك؟

لقد اتخذ الشاعر من الجغرافيا وسيلة للتعبير عن الحتمية الوجودية؛ فجعل الحياة في كاثورلا القريبة من جيان والموت في سانلوكار المتاخمة للمحيط

\footnotetext{
${ }^{3}$ Machado Ruiz, Antonio. Nuevas canciones, p. 33.
}

\begin{tabular}{|l|r|}
\hline allí los otros & والواصلون، وكلهج سواسية \\
medianos & \\
y más chicos; & \\
y llegados, son & \\
iguales & \\
los que viven por sus & \\
manos & \\
y los ricos. & \\
\hline
\end{tabular}

هنا يرمز للموت بالنهر الذي يتوقف بعد مسيرة جارفة، ولا ريب أن نصه هذا من مرثيته الثهيرة لوالده قد ترك أثرًا عميقًا في نفوس الثعراء الإسبان في العصر الحديث في تعاطيهم مع ظاهرة النهر الذي يخترق إسبانيا بكل غطرسة لكنه في نهاية المطاف يتلاشى في المحيط ويموت، كما أن تشبيهه النهر بالحياة وبالإنسان، والانصبابَ في المحيط بالموت، قد لقي صدئً واسعًا في نصوصهم، وقد رأينا كيف تمثلت فكرة الأنهار الكبيرة/البشر العظماء والأنهار الصغيرة/ البشر الضعفاء في نص الشاعرة الإشبيلية ماريّا ذي لوس رييس فوينتس على نحو لافت ومحوري. بدوره يقول أنطونيو ماتثادو مقتفيًا أثر مانريكي1

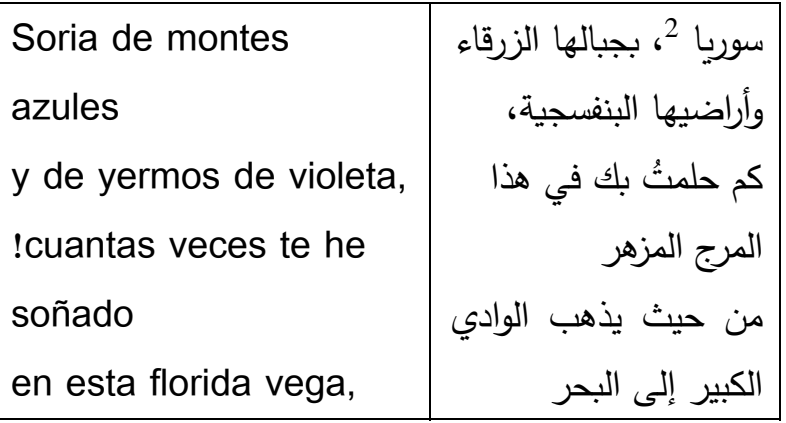

${ }^{1}$ Machado Ruiz, Antonio. Nuevas canciones, p. 13. مدينة صغيرة تقع في إسبانيا في منطقة قشتالة وليون، وليست البلد العربي

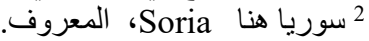


"روح قرطبة وإشبيلية" ربما يطوي أيضًا إشارة للموت بإزاء الحياة؛ فإذا كانت الروح مادة الحياة الأولى فالنهر بـانه الذي "يحمل الدم والتنهيدات" فاقد لكمال الحياة، وهو إلى لازمة الموت أقرب وبها أولى. وإذا كان النهر لهري

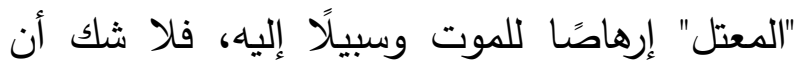
البحر، والمقصود به هنا المحيط الأطلسي، يمثل الموت والنهاية. والحق أنه من دواعي التأمل اقتران

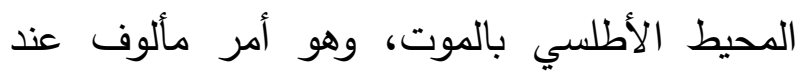
الشاعرة وعند غيرها، ولعل هذا المحيط قد مثل للشاعر الإسباني قلقًا وجوديًا لأن التقاءه بالأنهار يعني انتهاء مسيرها تمامًا فهو إذن كالموت الذي ينهي مسيرة البشر باختلاف أحوالهم، والوادي الكبير قسيم هذا الإنسان ورمزه الأبدي.

ثم إن المحيط الأطلسي في الذاكرة الثعبية الإسبانية كان آية على المغامرة المميتة، ولا شك أنه كذلك عند الأندلسيين؛ فقد عرف عندهم بما يعبر عن أثره فيهم "بحر الظلمات"، وحكاية الفتية المغررين الثمانية الذين

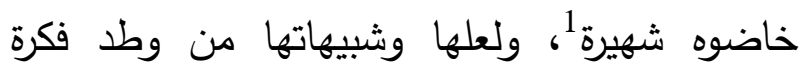
البحر/الموت في الوجدان الإيبيري. وهذا البحر رمز ونئي

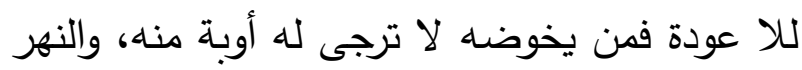

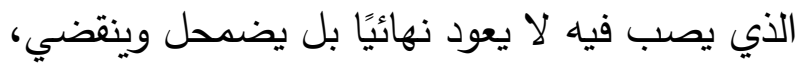
واللافت أن النهر يحكم على نفسه بالنهاية تحدوه

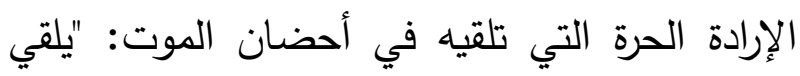
بنفسه في البحر نهائيًا من قرطبة"، والإشارة هنا لمسيرة
الأطلسي. إن المكان هنا علامة مزدوجة تشير للحياة

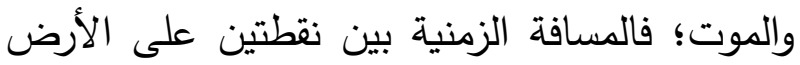
أولاهما بداية والأخرى نهاية تجسيد لموقف الإنسان بينهما، وما سعي النهر في الأرض إلا كسعي البشر لهر لهري فيها وكلاهما محكوم بخاتمة. ورغم هذه التجارب الدالة، تظل-في نظري- الثاعرة الإثبيلية ماريا ذي لوس رييس فوينتس خير من تناول فكرة الجمع بين النهر والنهاية، في نصيها اللذين عالجناهما في الثق الأول من هذه الدراسة: هذا النهر العابر خلال روح قرطبة وإثبيلية يحمل الدم والتنهيدات من الرحيق إلى بتلة قرطبة وإشبيلية

يلقي بنفسه في البحر نهائيًا من قرطبة معطيًا

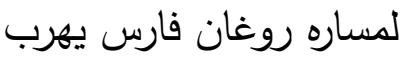

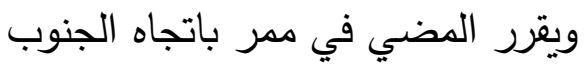

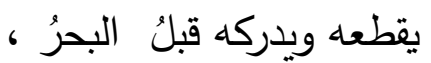
قبلُ المجدُ أو الموتُ.

تعلو هذه المقطوعة مسحة من الحزن والكآبة، مردها شعور دفين بألم النهاية/الموت خضب اللوحة باللون الأسود القاتم. بدا نهر الوادي الكبير معادلًا موضوعيًا للألم والموت، مخالفًا بذلك تقاليد طويلة استقر فيها الماء في أذهان الثعراء رمزًا للفأل والراحة. إنه "النهر العابر" ذو الانطلاقة نحو غاية، ولا غاية في النص إلا التلاشي والموت، واقتران النهر في عبوره بالأرواح

1 انظر الإدريسي، الثريف أبو عبد الله محدد، نزهة المشتاق في اختراق

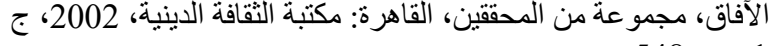


الموت لا الحياة مثل الهروب والجريان المنبئين عن اضطراب حركي وتسارع مردهما تعقب الموت للأحياء، حتى الحياة وستها أحيانًا بالعبثية واللا تلات

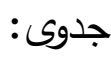
وفي كل زوايا الأرض تدفق الأنهار والبشر ، تسيل وتجري، الأن لتسكب في بحرها -المحكوم عليه بثدة-

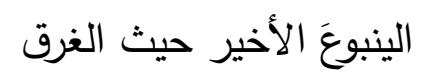$$
\text { مع تمزقات الهروب. }
$$

إن الإنسان، كالنهر ، جريان، هروب،

ندم؛ يمضي في البدء مندفعًا ثم يستكنّ في حين، لكن يظل قدمًا، لئاء في الركض -غير المجدي-للاقيقة بعد الدقيقة. إنها حياة مغرغة من معانيها، وليست حركتها إلا دليلًا

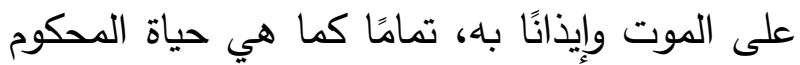
بالإعدام لا قيمة لها ولا سعادة فيها. إن النهر وقسيمه الإنسان، موجودات في خدمة العدم، يقتات عليها الموت حتى وإن كانت عظيمة؛ إذ لا قيمة لعظمتها وهي كغيرها مرتهنة للنهاية المحتومة. وفي النفس ما يحمل على القول بأن نصي الثاعرة هذين ولادا من رحم الماضي العربي الآقل ومن وحيه، حين كانت إثبيلية حاضرة الحواضر في الأندلس، وبالأخص زمن دولة بني عباد. فالثاعرة ابنة إثبيلية وفي جيلها نما شعور انتماء كبير للأندلس، لعله ألهب عواطف الثاعرة، خاصة النهاية المرة للمعتدد بن عباد بالتحول من طريق البحر إلى حيث النهاية والموت في
الإنسان فهو مندفع باختياره إلى نهايته، وهنا تتأزم الحالة الفكرية للإنسان -الدكنى عنه بالنهر -ما بين الجبرية والاختيارية؛ فهو مدفوع للموت ومندفع إليه في بي

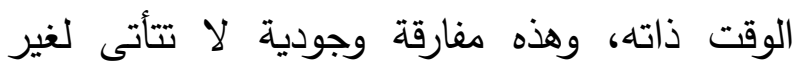
الإنسان: - المان وفي نصها الآخر المعنون بـ "النهر" يمكن التقاط بعض المشاهد المهمة: النهر مثل ذراع عدالة حكمه يأتي في الأخير : العبور ، العبرة. موقف المحاكمة هذا يلعب فيه نهر الوادي الكبير دورًا حيويًا لارتباطه بإصدار الأحكام، ولأنه قضاء نهائي لأئي لا رجعة فيه، لا يستت إلا في المرحلة الأخيرة من لإنائ التقاضي، كما هو النهر الذي يتأجل حكمه/نهايته لحين اتصاله بالمحيط، ويكون امتداده وجريانه شبيهًا بجريان أي قضية طويلة يحكم فيها في النهاية بإعدام المتهم. ونهر الوادي الكبير هنا، ما أن يصل للمحيط فيط لئل حتى يحكم بالإعدام على نفسه بنفسه ليكون قد عبر العبر

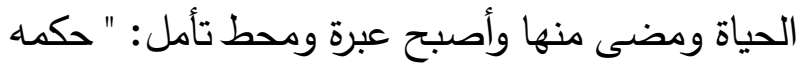
يأتي في الأخير : العبور ، العبرة". إنها مساقات حياتية إناتيات معقدة؛ متساوقة أحيائًا ووتنافرة أحيانًا أخرى. وقد أكدت الثاعرة على تماهي الإنسان مع النهر الأنا بجامع الانطلاق في مسالك الأرض إلى قدر محتوم، الإنان

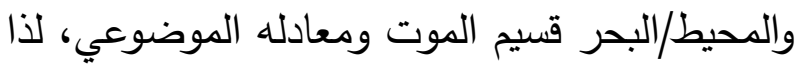
جرى التعبير عن الموت والنهاية بلفظ "الغرق". والظاهر أن نصي الشاعرة انبنيا ابتداءً على مفهوم النهاية؛ ولذلك نجدها تستعين كثيرًا بما يخدم فكرة 
الموت، ملحًا لدى الثاعر الأندلسي وهو يستعين بنهر

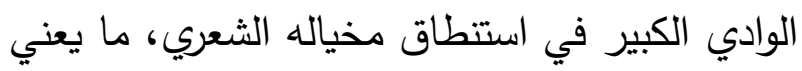
اعتداده بالحياة أكثر من الموت، وأن الوجه المشرق

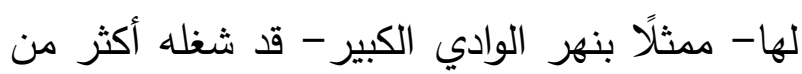

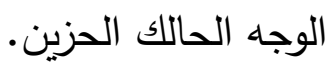
أما في سائر نصوص الوادي الكبير التي استعرضناها، المنتمية للأدب الإسباني القديم والحديث؛ فيمكن القول إجمالًا بأنها قد أبانت عن تماهِ

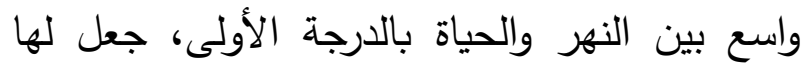
فيضًا وسيلانًا وله ولادة ونموًا وانكماشًا، على أن لناهي

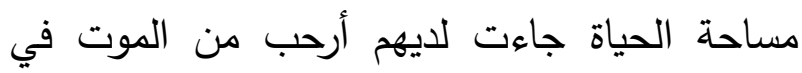
الغالب من نصوصهم الواردة في الدراسة. إن ما تمخض عنه البحث يدفعنا إلى القول بأن نهر الوادي الكبير في الثقافة الإسبانية عامة قد شكل معادلًا موضوعيًا للحياة والموت في آن واحد، على النى أن التجربة الإسبانية الحديثة تظل أكثر تعدقًا وشعورًا بنهر الوادي الكبير الذي اتخذ معها بعدًا وجوديًا عميقًا

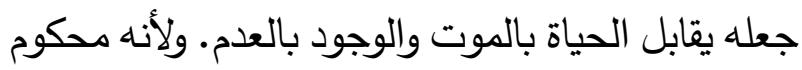
بنقطة ابتداء وانتهاء فقد تركب على حركة الإنسان في ولادته ومماته وبينهما ركضه الدؤوب الحافل بالأحداث. وقد اتخذ الأمر بعدًا عدميًا تثاؤميًا عند بعض الثعراء الإسبان لثدة اعتدادهم بفكرة النهر

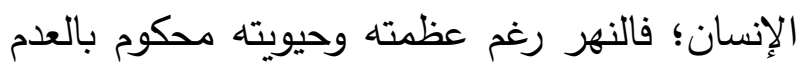
لأن مصيره النهاية في المحيط، وكذلك العمر وخاتمته التي لا مناص منها: "الكوت" ولا شيء غيره.
منفاه بالمغرب، واستعملت الوادي الكبير رمزًا لذلك؛ فهو يتتاهى في المحيط كليًا، لكن تظل ذكراه متوهجة

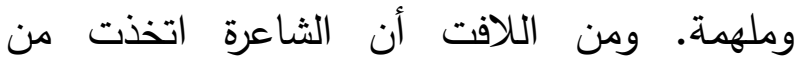
(الهروب) مكافنًا للجريان ومعادلًا لله، في إشارة إلى الثى الإنسان، يحاول الهروب من مصيره ثم يلقاه في نهاية المطاف، تماءًا كالنهر الذي يتبدد في المحيط؛ ذلك الهائل الذي يرمز للنهاية والاحتواء القاتم: "إن الإنسان، كالنهر ، جريان، هروب...". والحقيقة أن بعدًا وجوديًا يطوق النصين، وفيهما مسحة الابحة ظاهرة من تأملات شوبنهور ونيتشة؛ إذ النهاية المحتومة تبعث على التلبك حيال جدوى الحياة وأهمية تانية العيش، ولعل الغابر العربي الذي تلاشى في إثبيلية وغيرها فذهب الناس وبقيت آثارهم؛ قد ترك في نفس لفس إنسابر

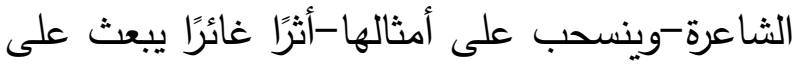
التنكر في طبيعة الوجود وجدواه: إن الإنسان، كالنهر، جريان، هروب، ندم؛ يمضي بدءا مندفعا ثم يستكن في حين، لكن يظل قدما، في الركض -غير المجدي-للدقيقة بعد الدقيقة.

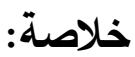
لامس العمل التجربة الثعرية الأندلسية إزاء نهر الوادي الكبير، وكثف عن حضوره مكونًا أساسًا وركيزة من ركائز الطبيعة التي شغف بها الأندلسيون، على اعتبار ما مثله من بعد لوجوديتهم، لكنه في العموم بقي في طور المسلك الذي يتوصل به لسائر

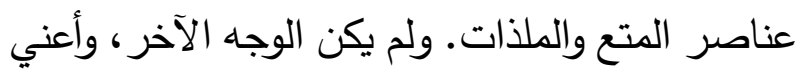




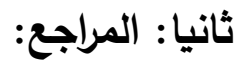
-المراجع العربية والمترجمة: باشلار، غاستون، الماء والأحلام، ترجمة: علي نجيب إبراهيم، بيروت: المنظمة العربية للنشر ، .2007

بنحمادة، سعيد، الماء والانسان في الاندلس - خلال القرنين 7 و 8 هـ / 13 و 14 م - إسهام في دراسة الهداء المجال والمجتمع والذهنيات، بيروت : دار الطليعة ل ل لطباعة والنشر ، 2007. بنفنيست، إميل، السيميولوجيا واللغة، ترجمة: سيزا قاسم، مجلة فصول، المجلد 1، العدد3، 1981. بنكراد، سعيد، السيميائيات مفاهيمها وتطبيقاتها، سوريا: دار الحوار، ط3، 2012. - السميائيات والتأويل، مدخل لسميائيات ش.س. بورس، بيروت-الدار البيضاء: المركز الثقافي العربي، 2005. الجديعي، محمد، المائيات في الثعر الأندلسي دلي عصر ملوك الطوائف، ماجستير، جامعة أم القرى، .2015

سلطان، هبة، أثز الماء في القصيدة الأندلسية،

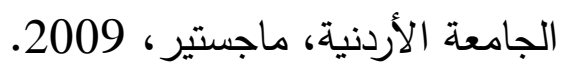
الثكعة، مصطفى، الثعر الأندلسي موضوعاته وفنونه، بيروت: دار العلم للملايين، ط4، 1979. شولز ، روبرت، السيمياء والتأويل، ترجمة: سعيد الغانمي، بيروت: المؤسسة العربية للدراسات والنشر،

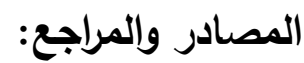

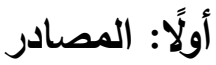

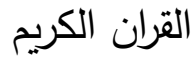
ابن الأبار، المقتضب من كتاب تحفة القادم، ت. إبراهيم الأبياري، القاهرة-بيروت: دار الكتاب المصري-دار الكتاب اللبناني، ط3، 1989. ابن خفاجة، ديوان، تحقيق: عبد الله سندة، بيروت: دار المعرفة، 2006، ص 208. ابن رشيق، العدة في صناعة الثعر ونقده، تحقيق: محمد محيي الدين عبد الحميد، بيروت: دار الجيل،

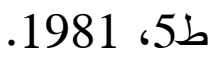
الإدريسي، الشريف أبو عبد الله محمد، نزهة المشتاق في اختراق الآفاق، مجموعة من المحققين، القاهرة: مكتبة الثقافة الدينية، 2002. ابن ظافر، علي، بدائع البدائه، ضبطه وصححه: مصطفى عطا، بيروت: دار الكتب العلمية، 2007. أبو نواس، ديوان أبي نواس برواية الصولي، تحقيق: بهجت الحديثي، أبو ظبي: هيئة أبو ظبي للثقافة نوانة والتراث، دار الكتب الوطنية، 2010. المقري، أحمد بن محمد، نفح الطيب من غصن الأندلس الرطيب، تحقيق: إحسان عباس، بيروت: دار

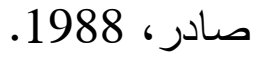


Jiménez Martos, Luis. Abrazo al Guadalquivir. Colección Córdoba. Diario Córdoba y Cajasur 1996.

Machado, Manuel y Antonio. Obras Completas. Madrid: Plenitud, 1957, $3^{\circ}$ ed.

Machado Ruiz, Antonio. Nuevas canciones. Poesías completas, España:

Rincon Castellano 1997 - 2011. (edición digital).

Manrique, Jorge. Coplas a la muerte de su padre y otros poemas, Sevilla: Alfar, 2014; $2^{\circ}$ ed.

Martínez Ortega, Carmen Elena, La obra poética de María de los Reyes Fuentes, tesis doctoral, Sevilla, 2011.

Molina, Ricardo. Aún es Córdoba Bella. Antología poética. Selección y prólogo: Carlos Clementson, España: Junta de Andalucía, 2017. Naranjo Mesa, Jorge Alberto. Poesía del Renacimiento y el Barroco . Colombia: Universidad de Antioquia, 2005.

Pineda Novo, Daniel. "Antonio Machado, exegeta del Guadalquivir". Boletín del Instituto de Estudios Giennenses, N. 66, 1970, pp.41-68. Solano Márquez, Francisco. Un río de versos. Rincones de Córdoba con encanto. Diario Córdoba 2003.

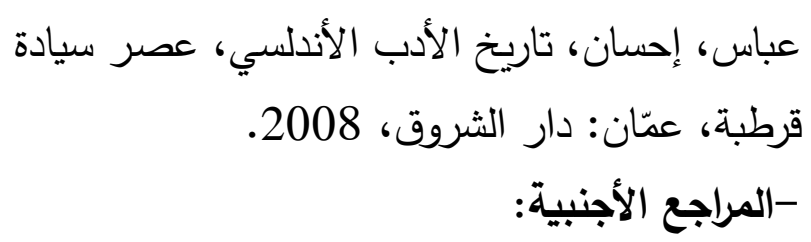

De la Cueva de Garoza, Juan. La Conquista de la Bética. Madrid: imprenta Real, 1795.

De Góngora y Argote, Luis. Poesías escogidas, Córdoba: Imprenta de Noguér y Manté, 1841.

Eslava Galán, Juan. Viaje por el Guadalquivir y su historia, Madrid: La Esfera de los Libros, 2016.

Fiesta de la Poesía Árabe. IX Centenario de Aben Házam, 12 al 18 de mayo. Córdoba, 1963.

Fuentes, María de los Reyes. Elegías del Uad el-kebir. Excmo., Sevilla: Ayuntamiento de, 1961.

Glendinning, Nigel: "The philosophy of Henri Bergson in the poetry of Antonio Machado", Revue de littérature comparée, 36 (1962), pp. 50-70.

Jerónimo de Salas Barbadillo, Alonso. Obras de Alonso Jerónimo de Salas Barbadillo, Madrid: Tip. de la Revista de Archivos, 190709. 


\title{
The symbolism of the "Guadalquivir" in Andalusian and Spanish poetry A comparative study in selected models ${ }^{1}$
}

\author{
Dr. Saleh Eazah Al-Zahrani \\ Associate Professor at King Saud \\ University - College of Arts - Department of Arabic Language
}

\begin{abstract}
. this study deals with a clear phenomenon that enjoys remarkable representations in ancient and modern Spanish poetry, which lies in the impersonation of the famous "Guadalquivir" river in the Spanish south, as a symbol with which the poem tries to embody the permanent attraction between man and the existential phenomena around him. The reading aims to analyze this relationship and deconstruct it into major signs that are seized by the duality of death and life. The study selected texts from Spanish poetry in ancient and modern times for the most important poets who considered the Guadalquivir river to be a deep substance, so they relied on it to form the poem objectively and artistically. At the beginning of the study, a flickering reference to the Andalusian experience in this subject shows the preoccupation of the Andalusian poets in superficial matters, while Spanish poets was preoccupied with something deeper than that, bound by the higher existential value of the Guadalquivir River.
\end{abstract}

Key words: Spanish poetry, symbolism, Guadalquivir.

\footnotetext{
${ }^{1}$ The author expresses his deepest appreciation and thanks to the Deanship of Scientific Research at King Saud University, represented by the Research Centre at the College of Arts, for funding this research. He also extends his thanks to RSSU at King Saud University for their technical support.
} 